\title{
Hedging the Risks of MENA Stock Markets with Gold: Evidence from the Spectral Approach
}

\author{
Awatef Ourir $^{1}$ (D) Elie Bouri $^{2}$ (D) $\cdot$ Essahbi Essaadi $^{3}$
}

Accepted: 10 September 2021 / Published online: 2 October 2021

(C) The Author(s), under exclusive licence to Springer Science+Business Media, LLC, part of Springer Nature 2021

\begin{abstract}
In this paper, we contribute to the old debate on the dynamic correlation between gold and stock markets by considering a spectral approach within the framework of portfolio hedging. Specifically, we consider eight MENA stock markets (Tunisia, Egypt, Morocco, Jordan, UAE, Saudi Arabia, Qatar, and Oman) and examine the optimal composition between gold and the stock market index, with a minimum portfolio risk and a high expected return. Based on the spectral approach, we propose seven portfolio structures and evaluate them through a comparison with the conventional DCC-GARCH method and the most best 10 portfolios constructed by using wavelet approach. The main results show that the spectral-based approach outperforms the DCC-GARCH and the wavelet methods. In fact, the optimal goldstock composition depends on the spectral density of each stock market index, where a stock market index with a stable spectral density requires more investments in gold than a stock market index with an unstable spectral density.
\end{abstract}

Keywords Hedge ratio - Evolutionary spectral analysis - DCC-GARCH model $\cdot$ Gold $\cdot$ Stock market index

JEL Classification G11 · C10 · C61

Essahbi Essaadi

Essahbi.Essaadi@gmail.com

Awatef Ourir

awatefourir@gmail.com

Elie Bouri

elie.elbouri@lau.edu.lb

1 Laboratory QuARG UR17ES26, University of Jendouba, FSEJG, Jendouba, Tunisia

2 School of Business, Lebanese American University, Beirut, Lebanon

3 University of Manouba, ESCT, QuARG UR17ES26, Campus Universitaire Manouba, 2010 Tunis, Tunisia 


\section{Introduction}

Stock markets play a key role in economic activity. They become the mirror of the health of each economy. When businesses are growing and the economy is expanding, investors are returning to the stock markets to take advantage of this expediency. Not only does the economy grows, but its fundamental structure changes across time. The changes in several economies and their opening to the international markets supported the increase in the frequency of shocks and crises in such markets. In looking for opportunities, many investors give attention to the potential risk of these actions, so to hedge, they diversify their portfolios and/or purchase derivative products that limit their losses.

After the double COVID-19 crisis (supply and demand crisis) on the oil market and the fall in prices below zero, gold seems to always be a safe haven, and that it still retains its function as a store of value. Besides, due to a lack of futures market in MENA $^{1}$ economies we suggested a gold as hedge alternative in the stock market. As a part of their culture, gold occupies an important part of life in the MENA countries. The volatility and correlation dependency and interdependency for financial series among different markets are assumed to be time-varying due to the presence of shocks and structural changes. Under these circumstances, we investigate the dynamic relationship between two financial indicators (gold and stock markets) for selected MENA countries. While including gold in the portfolio reduces volatility, we can conclude that gold can provide diversification and hedging for investors. Using evolutionary spectral analysis, we can examine the time-varying relationship at different frequencies.

The novelty of this study is two-fold. To our knowledge, we are the pioneers in studying the interdependence between gold and the stock market index for the MENA region as a whole. Our study extends also the related literature by using a non-parametric measurement that is based on the definition of the spectrum introduced by Priestley $(1965,1996)$ and which respects the properties emphasized by Loynes (1968). However, previous studies that introduced frequency analysis use wavelet theory. In the present study, we analyze the dynamic dependence between series. Our measure of time-varying coherence gives not only the dynamics of the correlation process but also indicates the frequencies at which they comove. Therefore we can determine the nature of the dynamic correlation process for a short run (high frequencies) and/or long run (low frequencies). The advantage of the frequency approach is that it detects the variability in the dependence process at different time scales. With this additional information, we can know which cycles are more relevant for each market. The use of frequency-domain allows us to distinguish between the properties of each cycle and to estimate the dynamic hedge ratio in each cycle. Using a nonparametric approach of spectral approach, we use seven possibilities to construct a hedged portfolio for each frequency. These frequencies correspond to a specific period $T$, which calculate by the ratio of $2 \pi / w$, where $w$ is the studied frequency.

\footnotetext{
${ }^{1}$ In this paper, we consider a sample of height the Middle East North Africa countries: Tunisia, Morocco, Egypt, Jordan, Oman, Qatar, UAE, Saudi Arabia.
} 
The remainder of the paper is organized as follows. Section 2 presents the literature review for different hedging strategies and related analyses. Section 3 focuses on the methodology adopted in this paper. Section 4 presents data and analysis of empirical results. Section 5 concludes.

\section{Related Literature}

Gold is one of the most relevant commodities in the world economy, as it performs several key functions in various markets. It is used as a store of value, an exchange means, and a complement to international reserves. It has long been recognized as a good hedge and a safe haven for financial assets, and particularly stocks. Compared to other safe-haven assets, the dependence between gold and stocks has attracted attention as this relationship has direct implications on the portfolio composition and risk management. However, modeling and understanding the degree and structure of the dependence between these two asset classes have attracted the attention of several studies ${ }^{2}$. Some confirm whereas others deny the role of gold in equity portfolios.

The first strand of studies uses the GARCH family to estimate variancecovariance relation between different assets and, construct a hedged portfolio. Some authors, such as Iqbal (2017), have not provided clear-cut results. He confirmed that hedging role of gold against adverse movement of stock is more complex than indicated in a linear relationship. Using the EGARCH model applied to daily and monthly data of gold price and India, Pakistan, and the United States stock prices, he found that the hedging potential of gold is not uniformly strong but is dependent on the state of the gold market. For its part, Ku et al. (2007) compared various hedging portfolio strategies to investigate the optimal hedge ratios of British (BP) and Japanese (JY) currency futures markets. Firstly, they applied the DCC and CCC-GARCH models to estimate the time-varying hedge ratio. Then, the OLS and the Error Correction Model are used to presume a time-invariant hedge ratio. Their main finding proves that the DCC-GARCH model yields the best hedging performance in both the JY and BP markets. Although it is well known that the time-varying hedging ratio is more realistic they confirmed that dynamic conditional correlations can better capture the frequent fluctuations. In the same vein, relying on the DCC-GARCH model, Creti et al. (2013) investigated the links between price returns for 25 commodities and stocks, by paying particular attention to gold. They show that the correlations between gold and stock markets evolve through time and are highly volatile, particularly since the financial crisis and, they found evidence of a negative correlation between the S\&P 500 stock market index and gold price, allowing gold to serve as a refuge value function. In 2016, Basher and Sadorsky (2016) come to enrich previous studies and use the DCC, ADCC, and GO-GARCH to model volatilities and conditional correlations between 23 emerging markets stock prices and gold prices. They found that hedge ratios estimated from the GOGARCH are the most effective for hedging stock prices with gold, but only after the

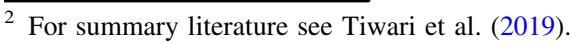


2008-2009 recessions. They suggest that their results are reasonably robust to the choice of model refits, forecast length, and distributional assumptions. Besides, Kumar (2014) reviewed portfolio designs and hedging effectiveness of gold in the Indian stock market. Using the VAR-ADCC-BVGARCH model, negative values of estimated time-varying conditional correlations are mainly observed during periods of market turbulence and crisis. This result indicates the scope of portfolio diversification and hedging during these critical periods. They also estimate optimal weights, hedge ratios, and hedging effectiveness for the stock-gold portfolios. Their findings suggest that a stock-gold portfolio provides better diversification benefits than stock portfolios. The same result has been confirmed by Chkili (2016) for BRICS $^{3}$ countries: gold is a refuge value.

The second strand of the literature proposes several techniques for measuring gold's ability to cover a portfolio of the stock market index. With a sample of major emerging and developing countries over 30 years, Baur and McDermott (2010) used a specific econometric approach to measure the degree of dependence between gold price and stock markets evolution. They showed that gold is both a hedge and a safe haven for major European stock markets and the US, but not for Australia, Canada, Japan, and large emerging markets such as the BRIC countries. Thereafter, using Generalized Method of the Moment, Ziaei (2012) found a strong adverse correlation, giving gold a convenient hedging statue for ASEAN $+3^{4}$ countries with quarterly data. As confirmed by Ciner et al. (2013), they tried to examine time variation in conditional correlations to determine if gold acts as a hedge of stocks portfolio. They investigated the dynamic correlations between gold and stock markets of US and UK nations using the quantile regression methods. They found that gold can be regarded as a safe haven against exchange rates for both countries, highlighting its monetary asset role. Otherwise, both Gokmenoglu and Fazlollahi (2015); Bouri et al. (2017) examined the inter-relationship between gold and financial markets through the co-integration test and nonlinear causality. They found a strong relationship between gold price and India and American stocks markets respectively. Raza et al. (2016) reported different results depending on the markets. According to a non-linear ARDL approach, they found that gold price has a positive impact on stock market prices of large emerging BRICS economies and a negative impact on Mexico, Malaysia, Thailand, Chile, and Indonesia stock markets. Gold volatility harms stock markets of all emerging economies in both the short and the long run. The results indicate that stock markets in emerging economies are more vulnerable to bad news and events that result in uncertain economic conditions. The dynamic relationship among gold and USD exchange rates is examined by Dong et al. (2019) and a negative association is shown while indicating the significance of structural breaks on the relationship. Using the quantile-on-quantile approach, they argued that dependence between stock-gold is not uniform and this relationship is market state and country-specific. Likewise, using the bivariate cross-quantilogram in the US market, Baumöhl and Lyócsa (2017) showed that the safe-haven properties of gold have a changing nature. Before

\footnotetext{
3 BRICS countries include Brazil, Russia, India, China, and South Africa.

4 The members of the Association of Southeast Asian Nations along with China, Japan, and South Korea.
} 
and after the financial crisis, gold can be considered a safe haven, but in the stress period, there are few sectors for which gold checked the relation. Tiwari et al. (2019) studied the dependence between gold and the stock market for seven emerging economies during 2002-2018. The study combined the bivariate crossquantilogram with quantile-on-quantile regression (QQR) approaches. They suggested that gold may be a hedge for stocks during the pre-crisis compared to the post-crisis period. Further, international risk factors should be considered in optimal investment decisions between domestic and global markets' assets (stocks and gold).

The third strand of literature uses the frequency approach to measure the relevance of gold in stock market portfolios. Baruník et al. (2016), by employing a time-frequency approach with a wavelet methodology, analyzed dynamic correlations especially between gold and stocks, and they used the volatility and the DCCGARCH approaches for comparison. For the United States daily and intra-daily data, they checked heterogeneity correlations between gold and stocks. Bouri et al. (2017) applied a frequency approach to check causality dynamics between gold and Chinese and Indian stock markets. They found significant bi-directional effects between both series in both high and low frequencies, suggesting an unstable feature of gold as refuge value. However, using a hybrid wavelet-based Dynamic Conditional Correlation (DCC) approach, Bhatia et al. (2020) investigated the dynamic relationship between precious metals and stock markets in the time and frequency domain for major developed (G7) and emerging (BRICS) nations. Their results suggest that DCC between series varies with timescales in terms of dynamistic, persistence, and strength of the relationship. Some related studies consider continuous wavelet transformation in the oil-stock nexus (Ghosh et al. 2021) and provide evidence of contagious in the financial markets (Ftiti et al. 2015), especially during the US subprime crisis (Zhou 2017). Also, with a large sample of 34 emerging and developing economies, Bulut and Rizvanoghlu (2020) affirmed the hedge property of gold in stock markets. Using a GARCH-copula approach, they found that safe haven property varies from one country to another.

Although the majority of previous studies have verified the dependency relationship between gold price and stock markets index, to confirm the hedging property and refuge character of gold. This relationship varies over time in terms of sign and intensity. Given this variability, the composition of an optimal portfolio (gold - stocks) varies also according to the degree of existing dependence between them. To detect this dynamic relationship, we use an evolutionary spectral analysis and propose a statistic of coherence and its components based on a frequency approach. Our study allows us to decompose movements according to their component cycles and also allows those cycles to vary in importance and characteristics over time. Considering these properties and the specificity of the MENA stock markets, this paper extends previous studies by examining the hedging character of gold at the expense of the derivatives market, using the evolutionary spectral analysis defined by Priestley $(1965,1996)$. 


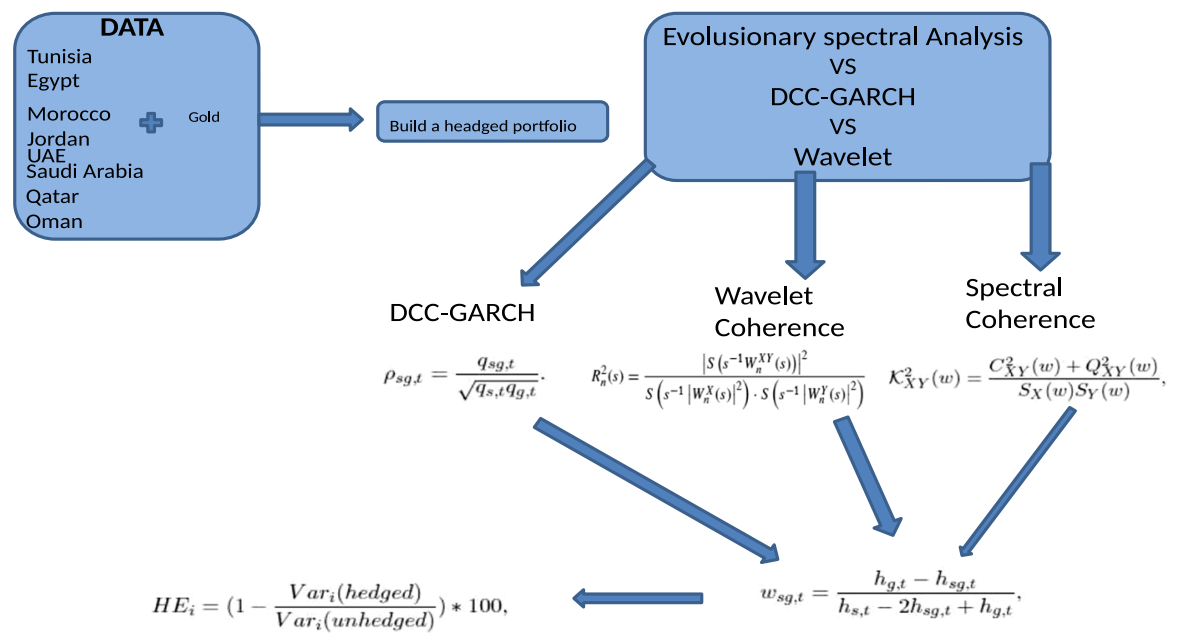

Fig. 1 Methodological steps

\section{Empirical Methodology}

There are two well-defined approaches to analyzing time series: Spectral Approach (frequency approach) and Temporal Approach (dynamic approach). The interest of the spectral analysis is the simplicity in the visibility of the periodicity within the series. It, therefore, does not require upstream processing unlike the temporal approach that relies on the assumption of stationarity in mean, variance, and covariance after elimination of trends. In this paper, we compare hedge performance for the two different approaches using MENA countries' data. On one hand, relying on the presence of heteroscedasticity and dynamic in the interdependence between returns in the financial market, we use a widely employed DCC-GARCH model to estimate time-varying correlation and their components. On the Other hand, we propose a frequency alternative for correlation and hedge estimation. Figure 1 illustrates the main methodological steps that we follow in our empirical analysis.

\subsection{Dynamic Conditional Correlation-GARCH Model}

Introduced by Engel (2002), DCC-GARCH is widely used in financial time series modeling as presented in the previous section. The model is relying on a timevarying variance-covariance matrix decomposition. The multivariate DCC-GARCH model is presented as follows:

$$
r_{t}=\mu+\varepsilon_{t}, \varepsilon_{t} \sim N\left(0, H_{t}\right),
$$

where $r_{t}=\left(r_{s, t}, r_{g, t}\right)^{\prime}$ is the vector of log returns of stock market $s$ and the second for the gold log returns at tome $t, \mu=\left(\mu_{s}, \mu_{g}\right)^{\prime}$ is the vector of the expected value of the conditional $r_{t}, \varepsilon_{t}=\left(\varepsilon_{s, t}, \varepsilon_{g, t}\right)^{\prime}$ is the vector of conditional residual with $E\left(\varepsilon_{t}\right)=0$ and $\operatorname{Cov}\left(\varepsilon_{t}\right)=H_{t}$ the variance covariance matrix. 


$$
H_{t}=D_{t} R_{t} D_{t}
$$

where $H_{t}$ is a $2 \times 2$ matrix of conditional variance of mean-corrected k-return series $\left(r_{t}\right)$ at time $t, E\left(r_{t}\right)=0$ and $\operatorname{Cov}\left(r_{t}\right)=H_{t} . D_{t}$ is a $2 \times 2$ diagonal matrix of time varying standard deviations from 2 univariate GARCH models at time $t$.

$$
D_{t}=\left[\begin{array}{cc}
\sqrt{h_{s t}} & 0 \\
0 & \sqrt{h_{g t}}
\end{array}\right]
$$

The $R_{t}$ matrix represents the time varying conditional correlation matrix.

$$
R_{t}=\left(\operatorname{diag}\left(Q_{t}\right)\right)^{-1 / 2} Q_{t}\left(\operatorname{diag}\left(Q_{t}\right)\right)^{-1 / 2},
$$

where $Q_{t}$ has the $\operatorname{GARCH}(1,1)$ specification

$$
Q_{t}=(1-\alpha-\beta) \bar{Q}+\alpha z_{t-1} z_{t-1}^{\prime}+\beta Q_{t-1},
$$

The parameters $\alpha$ and $\beta$ are nonnegative with sum less than unity. When $\alpha=\beta=0$, we find a CCC-GARCH model.

$$
\bar{Q}=\frac{1}{T} \sum_{t=1}^{T}\left[\begin{array}{cc}
z_{s, t}^{2} & z_{s, t} z_{g, t} \\
z_{g, t} z_{s, t} & z_{g, t}^{2}
\end{array}\right]=\left[\begin{array}{cc}
\bar{\rho}_{s} & \bar{\rho}_{s g} \\
\bar{\rho}_{s g} & \bar{\rho}_{g}
\end{array}\right],
$$

where $z_{i, t}=\frac{\varepsilon_{i, t}}{\sqrt{h_{i, t}}}, Q_{t}$ is a $2 \times 2$ symmetric positive definite matrix.

$$
\begin{aligned}
q_{s, t} & =\bar{\rho}_{s}(1-\alpha-\beta)+\alpha\left(z_{s, t-1} z_{s, t-1}\right)+\beta\left(q_{s, t-1}\right), \\
q_{g, t} & =\bar{\rho}_{g}(1-\alpha-\beta)+\alpha\left(z_{g, t-1} z_{g, t-1}\right)+\beta\left(q_{g, t-1}\right), \\
q_{s g, t} & =\bar{\rho}_{s g}(1-\alpha-\beta)+\alpha\left(z_{s g, t-1} z_{s g, t-1}\right)+\beta\left(q_{s g, t-1}\right) .
\end{aligned}
$$

The conditional correlation $R_{t}$ at time $t$ is defined as follows:

$$
\rho_{s g, t}=\frac{q_{s g, t}}{\sqrt{q_{s, t} q_{g, t}}} .
$$

According to Engel (2002) we estimate the model with a two-step maximum likelihood method using the following equation:

$$
L=-\frac{1}{2} \sum_{t=1}^{T}\left(2 \log (2 \pi)+2 \log \left|D_{t}\right|+\log \left|R_{t}\right|+z_{t}^{\prime} R_{t}^{-1} z_{t}\right) .
$$

However, Dong and Yoon (2018) revealed that estimation of the DCC-GARCH model change if we introduce a structural break date in the model. For this reason, we propose an alternative to estimate the time-varying conditional correlation matrix without being affected by a structural change or other events. 


\subsection{Wavelet Coherence}

The wavelet coherence can be used to capture the co-movement between $X$ and $Y$ in both the time and frequency domains (Torrence and Compo 1998; Grinsted et al. 2004). It implements a bivariate framework based on a continuous wavelet transform (Aguiar-Conraria and Soares 2011) and can be regarded as the local covariance of $X$ and $Y$, having a length $T$.

The wavelet transformations of $X$ and $Y$ are respectively $W_{t}^{X}(s)$ and $W_{t}^{Y}(s)$, as given by:

$$
\begin{aligned}
W_{t}^{X}(s) & =\sum_{\tau=0}^{T-1} X_{j} \frac{1}{\sqrt{s} \Psi\left(\frac{t-\tau}{s}\right)}, \\
W_{t}^{Y}(s) & =\sum_{\tau=0}^{T-1} Y_{j} \frac{1}{\sqrt{s} \Psi\left(\frac{t-\tau}{s}\right)},
\end{aligned}
$$

where, $t$ denotes the time position, $s$ represents the scale, $\frac{1}{\sqrt{s}}$ is the normalization factor, and $\Psi($.$) is a localized wavelet.$

Using the Morlet wavelet (with the Morlet wavelet set to 6$)^{5}$, the cross-wavelet power spectrum between $X$ and $Y$ is computed as:

$$
W_{t}^{X Y}(s)=\left\langle W_{t}^{X}(s), W_{t}^{Y}(s)\right\rangle
$$

where $\left\langle W_{t}^{X}(s), W_{t}^{Y}(s)\right\rangle$ is the product of $W_{t}^{X}(s)$ and $W_{t}^{Y *}(s)$, with $*$ being the complex conjugate.

Then, the wavelet coherency between $X$ and $Y$ is the absolute squared value of the smoothed cross-wavelet spectrum, divided by the product of two smoothed wavelet power spectra. It is represented by:

$$
R_{t}^{2}(s)=\frac{\left|S\left(s^{-1} W_{t}^{X Y}(s)\right)\right|^{2}}{S\left(s^{-1}\left|W_{t}^{X}(\tau)\right|^{2}\right) \cdot S\left(s^{-1}\left|W_{t}^{Y}(s)\right|^{2}\right)},
$$

where $S($.$) is the smoothing operator over time as well as scale.$

The value of the wavelet squared coherence $R_{t}^{2}(s) \in[0,1]$, with a high (low) value showing strong (weak) co-movement between $X$ and $Y$.

The wavelet coherence approach can also be used to uncover the lead-lag relationship between $X$ and $Y$. The phase difference is represented as:

$$
\phi_{X, Y}=\tan ^{-1} \frac{\mathfrak{I}\left\{W_{X Y}(\tau, s)\right\}}{\mathfrak{R}\left\{W_{X Y}(\tau, s)\right\}}, \quad \phi_{X, Y} \in[-\pi, \pi]
$$

where, $\mathfrak{I}$ and $\mathfrak{R}$ represent the imaginary and real parts of the smooth power spectrum, respectively. The phase difference is represented by a directional arrow, where the arrow pointing to the right (left) reflects positively (negatively) correlated series. The arrow pointing upwards reflects the fact that the first series leads the

\footnotetext{
5 Details on the Morlet wavelet are provided by Addison (2017).
} 
other series by $\pi / 2$, and the opposite is true for an arrow pointing downward. In fact, we identify causality and phase differences between the returns of gold and the stock index. The arrows indicate the phase differences between the returns of gold and the stock index. For example, $\rightarrow$ and $\leftarrow$ indicate that the returns of gold and the stock index are in phase and out of phase, respectively. $\nearrow$ and $\swarrow$ indicate that gold returns lead stock index return, whereas $\searrow$ and $\nwarrow$ indicate that gold returns lag the returns of the stock index ${ }^{6}$.

\subsection{Frequency Approach: Evolutionary Spectral Analysis}

The spectral approach presented by Priestley $(1965,1996)$ is the reference for frequency analysis because it respects the properties of the ideal spectrum, namely unicity, positivity, the estimate from one realization (Loynes 1968). The frequencydomain approach improves our analysis in sixth ways. First, it does not depend on any particular detrending technique. Second, we do not have an 'end-point problem': no future information is used, implied, or required as in band-pass or trend projection methods. Third, there is no deletion of short or long cycles, so their importance relative to cycle frequencies remains clear. Fourth, the coherence measure generalizes on simple correlation or concordance measures. Fifth, this approach can be applied to stationary or non-stationary processes. Finally, it performs our time-varying analysis at different frequencies simultaneously. This allows us to separate the different dynamic components of the co-movement.

We denote $\left\{X_{t}\right\}$ the observable time series. The evolutionary aspect of the spectrum is related to the non-stationarity in this series which follows an oscillatory process.

$$
X_{t}=\int_{-\pi}^{\pi} A_{X}(w, t) e^{i w t} d Z_{X}(w),
$$

where for each $w$, the sequence $\left\{A_{X}(w, t)\right\}$, as function of $t$ admits a maximum Fourier transform (in module) in zero with $\left\{Z_{X}(w)\right\}$ an orthogonal process on $[-\pi, \pi], E\left[d Z_{X}(w)\right]=0, E\left[\left|d Z_{X}(w)\right|^{2}\right]=d \mu_{X}(w)$ and $\mu_{X}(w)$ a measure. The evolutionary spectral density of $\left\{X_{t}\right\}$ is the function $S_{X}(w, t)$ defined as follows:

$$
S_{X}(w, t)=\frac{d H_{X}(w, t)}{d w},-\pi \leq w \leq \pi
$$

where $d H_{X}(w, t)=\left|A_{X}(w, t)\right|^{2} d \mu_{X}(w)$. The variance of $\left\{X_{t}\right\}$ at time $t$ is given by:

$$
\sigma_{X, t}^{2}=\operatorname{Var}\left(X_{t}\right)=\int_{-\pi}^{\pi} S_{X}(w, t) d w
$$

\footnotetext{
6 The wavelet coherence estimation code has been downloaded from Grinsted website: http://www. glaciology.net/wavelet-coherence.
} 


\subsubsection{Presentation of the Coherence Function}

Coherence is interpreted as the linear squared correlation coefficient for each frequency of the spectra of two series. The time approach gives the instantaneous coherent peaks between two series and describes their patterns over time. Therefore for our case, it is crucial to know whether coherence has been increased or not between the cycles of some assets, so we can conclude if the assets are suitable to be included in the portfolio.

In the frequency domain, we define the correlation between two components in frequency as the coherence $(\mathcal{K})$. Consider two zero-mean stochastic processes $\left(X_{t} ; Y_{t}\right)$, let $S_{X}(w)$ and $S_{Y}(w),-\pi \leq w<\pi$, be the spectral density functions and $S_{X Y}(w)$ be the cospectrum. Each of the two processes can be written as:

$$
X_{t}=\int_{-\pi}^{\pi} A_{X}(w) e^{i w t} d Z_{X}(w), \quad Y_{t}=\int_{-\pi}^{\pi} A_{Y}(w) e^{i w t} d Z_{Y}(w) .
$$

where

$$
\begin{aligned}
E\left[d Z_{X}\left(w_{1}\right) \overline{d Z_{Y}\left(w_{2}\right)}\right] & =0 \quad w_{1} \neq w_{2} \\
& =S_{X Y}(w) d w, \quad w_{1}=w_{2}=w .
\end{aligned}
$$

where $\bar{Z}$ denotes the complex conjugate of $Z$. It is well-known that

$$
S_{X Y}(w)=C_{X Y}(w)-i Q_{X Y}(w),
$$

where

$$
\begin{aligned}
& C_{X Y}(w)=\mathfrak{R}\left\{S_{X Y}(w)\right\} \text { and } \\
& Q_{X Y}(w)=-\mathfrak{J}\left\{S_{X Y}(w)\right\}
\end{aligned}
$$

are the Real Cospectrum (the gain) and the Quadrature Spectrum (the phase) respectively. $\mathfrak{R}$ and $\mathfrak{I}$ are the real and the imaginary parts of the cross-spectrum.

The coherence $\mathcal{K}_{X Y}(w)$ at frequency $w$ is given by

$$
\mathcal{K}_{X Y}^{2}(w)=\frac{C_{X Y}^{2}(w)+Q_{X Y}^{2}(w)}{S_{X}(w) S_{Y}(w)},
$$

Eq. (37) verifies this inequality coherence, $C_{X Y}^{2}(w)+Q_{X Y}^{2}(w) \leq S_{X}(w) S_{Y}(w)$. Therefore $\mathcal{K}_{X Y}^{2}(w)$ cannot be greater than one. This statistic shows the degree of comovement between two series at the frequency $w$ and it is analogous to the coefficient of the correlation between the two samples in the time domain. The coherence measure provides more detailed information than the conventional correlation and concordance measures. 


\subsubsection{A Time-Varying Coherence Function (TVCF)}

In the time domain, a dynamic Pearson correlation can give us some crucial responses to this issue. However, the choice of window can seriously affect the dynamic correlation pattern (Essaadi et al. 2009). To overcome this limitation, we propose to measure the co-movement variability by the frequency approach. Timevarying coherence function estimates not only a degree of co-movement over time but also the behavior of its co-movement in each frequency. Through the TVCF, we can calculate the relationship between two financial data series, and their timevarying changes at each frequency. Our goal is to locate the estimated time-varying variance-covariance statistic of the series to estimate the optimal dynamic hedge ratio.

We introduce a new method to estimate time-varying coherence functions (TVCF) for financial portfolio design. We aim to present a new portfolio composition that outperforms the DCC- GARCH proposition by reducing risk and/or increasing returns.

The TVCF is a valuable tool for investigating dynamic interdependence problems and to review short-run and long-run dynamic properties of multiple time series. The meaning of this time-varying relationship is to conclude whether we should change our position by investing in financial assets or keep the money in a storage investment.

Priestley (1988) extends the theory of evolutionary spectra to the case of bivariate non-stationary processes. Consider two oscillatory component processes, $\left(X_{t} ; Y_{t}\right)$ : we can write

$$
X_{t}=\int_{-\pi}^{\pi} A_{X}(w, t) e^{i w t} d Z_{X}(w), \quad Y_{t}=\int_{-\pi}^{\pi} A_{Y}(w, t) e^{i w t} d Z_{Y}(w) .
$$

where:

$$
\begin{aligned}
E\left[d Z_{X}\left(w_{1}\right) \overline{d Z_{X}\left(w_{2}\right)}\right] & =E\left[d Z_{Y}\left(w_{1}\right) \overline{d Z_{Y}\left(w_{2}\right)}\right] \\
& =E\left[d Z_{X}\left(w_{1}\right) \overline{d Z_{Y}\left(w_{2}\right)}\right]=0 \text { when } w_{1} \neq w_{2} . \\
E\left[\left|d Z_{X}(w)\right|^{2}\right] & =d \mu_{X}(w), E\left[\left|d Z_{Y}(w)\right|^{2}\right]=d \mu_{Y}(w) \text { and } \\
E\left[d Z_{X}(w) \overline{d Z_{Y}(w)}\right] & =d \mu_{X Y}(w) .
\end{aligned}
$$

According to Priestley (1988), in the non-stationary case cross-spectrum is timevarying and is defined as $d H_{X Y}(w, t)$. By virtue of the Cauchy-Schwarz inequality, we have

$$
\left|d H_{X Y}(w, t)\right|^{2} \leq d H_{X}(w, t) d H_{Y}(w, t), \quad \text { for all } t \text { and } w .
$$

We can write

$$
d H_{X Y}(w, t)=S_{X Y}(w, t) d w
$$

where $S_{X Y}(w, t)$ is the evolutionary cross-spectrum density function. 


$$
S_{X Y}\left(w_{j}, t\right)=C_{X Y}\left(w_{j}, t\right)-i Q_{X Y}\left(w_{j}, t\right)
$$

where

$$
\begin{aligned}
& C_{X Y}\left(w_{j}, t\right)=\mathfrak{R}\left\{S_{X Y}\left(w_{j}, t\right)\right\} \text { and } \\
& Q_{X Y}\left(w_{j}, t\right)=-\mathfrak{I}\left\{S_{X Y}\left(w_{j}, t\right)\right\}
\end{aligned}
$$

are the Real Time-Varying Co-spectrum (the gain) and the Time-Varying Quadrature Spectrum (the phase) respectively. $\mathfrak{R}$ and $\mathfrak{I}$ are the real and the imaginary parts of the time-varying cross-spectrum.

\subsubsection{Estimate of the Evolutionary Spectrum and Cross-Spectra}

Estimation of $S_{X}(w, t)$ is performed by use of two windows $\left\{g_{u}\right\}$ and $\left\{w_{v}\right\}$

$$
\widehat{S_{X}}(w, t)=\sum_{v \in Z} w_{v}\left|U_{t-v}(w)\right|^{2}
$$

where $U_{t}(w)=\sum_{u \in Z} g_{u} X_{t-u} e^{-i w(t-u)}$. We choose $\left\{g_{u}\right\}$ and $\left\{w_{r}\right\}$ as follows:

$$
\begin{gathered}
g_{u}=\left\{\begin{array}{cc}
1 /(2 \sqrt{h \pi}) & \text { if }|u| \leq h \\
0 & \text { if }|u|>h
\end{array} \mid\right. \\
w_{v}=\left\{\begin{array}{cc}
1 / T^{\prime} & \text { if }|v| \leq T^{\prime} / 2 \\
0 & \text { if }|v|>T^{\prime} / 2
\end{array} \mid\right.
\end{gathered}
$$

Here $h=7$ and $T^{\prime}=100$. According to Priestley (1988) we have $E\left(\widehat{S_{X}}(w)\right) \approx S_{X}(w, t), \quad \operatorname{var}\left(\widehat{S_{X}}(w)\right) \quad$ decreases when $T^{\prime}$ increases and $\forall\left(t_{1}, t_{2}\right), \forall\left(w_{1}, w_{2}\right), \operatorname{cov}\left(\widehat{S_{X}}\left(w_{1}, t_{1}\right), \widehat{S_{X}}\left(w_{2}, t_{2}\right)\right) \approx 0$. If one of the two conditions $(j)$ and $(j j)$ is satisfied.

$$
\text { (j) } \quad\left|t_{1}-t_{2}\right| \geq T^{\prime}, \quad(j j) \quad\left|w_{1} \pm w_{2}\right| \geq \pi / h
$$

Let $S_{X}^{i w}=\log \left(S_{X}\left(w, t_{i}\right)\right)$ and $\Lambda_{X}^{i w}=\log \left(\widehat{S_{X}}\left(w, t_{i}\right)\right)$. From Priestley (1988), we have:

$$
\Lambda_{X}^{i w} \approx S_{X}^{i w}+e_{X}^{i w}
$$

where the sequence $\left\{e_{X}^{i w}\right\}$ is approximately normal, uncorrelated and identically distributed.

Following Priestley (1965, 1996), in an evolutionary spectral theory, Essaadi and Boutahar (2010) propose a time-varying cross-spectrum estimator using spectral density. Estimation of $S_{X Y}(w, t)$ is obtained by use of the 'double window technique' $\left\{g_{u}\right\}$ and $\left\{w_{v}\right\}$ given in (30) and (31).

$$
\widehat{S_{X Y}}(w, t)=\sum_{v \in Z} w_{v} U_{X}(w, t-v) U_{Y}(w, t-v),
$$

where $U_{X}(w, t)=\sum_{u \in Z} g_{u} X_{t-u} e^{-i w(t-u)}$ and $U_{Y}(w, t)=\sum_{u \in Z} g_{u} Y_{t-u} e^{-i w(t-u)}$. 
Here $h=7$ and $T^{\prime}=100$. According to Priestley (1988), we have $E\left(\widehat{S_{X Y}}(w)\right) \approx S_{X Y}(w, t), \quad \operatorname{var}\left(\widehat{S_{X Y}}(w)\right) \quad$ decreases when $T^{\prime}$ increases and $\forall\left(t_{1}, t_{2}\right), \forall\left(w_{1}, w_{2}\right), \operatorname{cov}\left(\widehat{S_{X Y}}\left(w_{1}, t_{1}\right), \widehat{S_{X Y}}\left(w_{2}, t_{2}\right)\right) \approx 0$, if one of the two conditions $(j)$ and $(j j)$ of (32) is satisfied.

To respect the $(j)$ and $(j j)$ conditions we choose $\left\{t_{i}\right\}$ and $\left\{w_{j}\right\}$ as follows:

$$
\left\{t_{i}=100 i\right\}_{i=1}^{I} \text { where } I=\left[\frac{T}{100}\right] \text { and } T \text { the sample size, }
$$

$[x]$ denotes the integer part of $x$.

$$
\left\{w_{j}=\frac{\pi}{20}(1+3(j-1))\right\}_{j=1}^{7} .
$$

Following $(j j)$ condition, we inspect instability in these frequencies: $\pi / 20,4 \pi / 20$, $7 \pi / 20,10 \pi / 20,13 \pi / 20,16 \pi / 20$ and $19 \pi / 20$.

\subsection{Variance Reduction Hedging Strategy}

The most widely optimal hedging portfolio strategy is to minimize variance by an optimal hedge ratio. We consider a portfolio composition that reduces risk without sacrificing return. We design our respective portfolios by calculating the weighting of the two assets as follows:

$$
w_{s g, t}=\frac{h_{g, t}-h_{s g, t}}{h_{s, t}-2 h_{s g, t}+h_{g, t}},
$$

and

$$
w_{s g, t}=\left\{\begin{array}{rll}
0, & \text { if } & w_{s g, t}<0 \\
w_{s g, t}, & \text { if } & 0 \leq w_{s g, t} \leq 1 \\
1, & \text { if } & w_{s g, t}>1 .
\end{array}\right.
$$

where $w_{s g, t}$ is the weight of the $S$ asset in a one-dollar portfolio of the gold-metals at time $t, h_{s g, t}$ is the conditional covariance between the stock market index and gold, $h_{s, t}$ is the conditional variance of the stock market index and $h_{g, t}$ is the conditional variance of the gold. The weight of the gold in a dollar's portfolio is $1-w_{s g, t}$. This strategy was adopted by several previous studies (Hammoudeh et al. 2010; Chkili 2016) to examine conditional volatility and correlation dependency for major precious metals and to develop portfolio hedging strategies. In the same line, Khalfaoui et al. (2015) propose a portfolio composed of oil and stock market based on the Eq 37 and 38. To compare different portfolio propositions, we estimate a hedging effectiveness ratio. Following Chkili (2016) hedging effectiveness is defined by the reduction in the variance of the hedge portfolio compared to the unhedged one.

$$
H E_{i}=\left(1-\frac{\operatorname{Var}_{i}(\text { hedged })}{\operatorname{Var}_{i}(\text { unhedged })}\right) * 100,
$$


where $i$ denote country $i$. In our case, the unhedged portfolio corresponds to the one where the investment share in the stock market is $100 \%$ as $\operatorname{Var}_{i}($ unhedged $)=\operatorname{Var}_{i}(S)^{7}$.

\section{Empirical Study}

\subsection{Data Presentation}

We use gold prices in USD and a selection of stock market indices for eight countries of the MENA region: Tunindex (Tunisia) 02/01/1998-30/03/2020 (5360 observations), EGY 30 (Egypt) 05/01/1998-30/03/2020 (4290 observations), MI (Morocco) 03/01/2002-30/03/2020 (4442 observations), Amman (Jordan) 11/01/ 2000-16/03/2020 (3881 observations), Dubai (United Arab Emirates) 05/01/200430/03/2020 (3230 observations), Tadawul (Saudi Arabia) 20/10/1998-30/03/2020 (3856 observations), Doha index (Qatar) 14/03/2001-30/03/2020 (3781 observations) and MSM 30 (Oman) 21/12/2000-30/03/2020 (3754 observations).

This study used daily data over the longest period available from the following website (https://www.investing.com/indices/), and only common price observations between gold and each stock index are considered. The return rate of series is calculated by the first difference of the logarithm of daily gold prices and stock indexes, as follows:

$$
r_{i, t}=\Delta\left(\log \left(X_{i, t}\right)\right)=\log \left(\frac{X_{i, t}}{X_{i, t-1}}\right),
$$

where $r_{i, t}$ is returns series of $i, i=s$ for stock market index and $i=g$ for gold price in USD. $X_{t}$ denotes the selected time series of gold price or stock indices. The descriptive statistics of the return series is presented in Table 1.

We restrict our analysis for two assets portfolio (gold-stock index). Note that for the need of an evolutionary spectral estimation (Figs 11, 12, 13, 14, 15, 16, 17 and 18), we lose 100 observations at the beginning. Therefore we apply a hedging ratio to $T-100$.

\subsection{Descriptive Analysis}

The descriptive statistic of the return series (Table 1) gives various results. The gold series is considered a reference series, its mean return and standard deviation are relatively small ( 0.0325 and 0.011518 respectively), reflecting the stable properties of the underlying assets. Some countries offer higher average stock market returns than gold, such as Tunisia, Egypt, Saudi Arabia, and Qatar, at the expense of others. Thus, investing in these stock markets is more profitable than gold. However, the study of the return variable remains incomplete without the market risk measure. Under this second indicator, a higher standard deviation of the stock market index of

\footnotetext{
${ }^{7}$ We summarize in Tables (3, 5 and 6 ) the results of the dynamic hedge ratio performance for a portfolio composed by the stock market index and gold.
} 


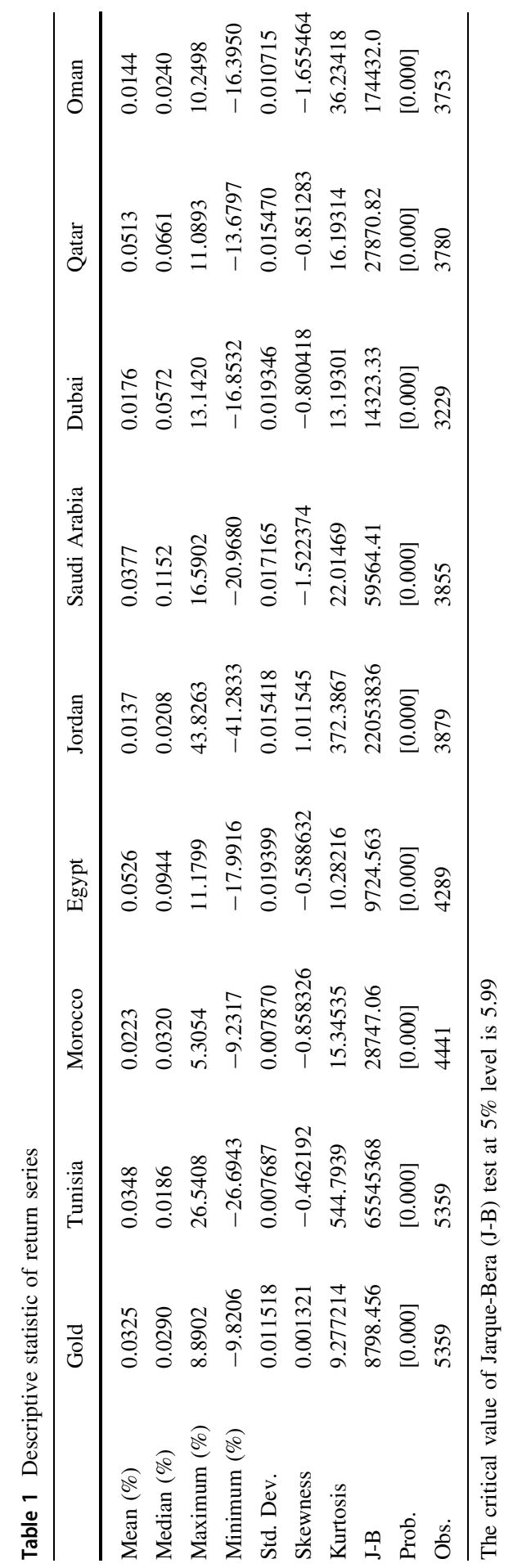


Egypt, Saudi Arabia, and Qatar, in addition to that of Jordan and Dubai relative to gold, is synonymous with price instability. These markets are volatile. Investing in these markets is profitable but it remains risky compared to gold. These are the main MENA markets affected by several economic, financial crises. Contrary to Morocco, Oman, and Tunisia, which are small developing markets, they are less risky and more stable due to their diversified economy. The rejection of the normality test, for all these series, is verified through the Jarque-Bera statistic, which is far from the critical value. This brings us to the question of the effectiveness of gold as a hedging instrument for these markets.

\subsection{Results}

The graph of the evolutionary spectral density of TUNINDEX (Tunisia) (Fig. 2) reveals an intense change in the short cycle in 2005 as the stock market achieved its second-best double-digit performance $(21 \%)$ since its creation. The second long cycle change occurred between late 2010 and early 2011, reflecting the Arab Spring revolution.

Qatar (Fig. 8) and Oman (Fig. 9) share a common graphical pattern, illustrated by a change in late 2008 and early 2009 marking the contagion of the US subprime crisis. This crisis has affected both low (long term) and high (short term) frequencies. We find the same conclusion as well as for Jordan. The end of 2005 and the beginning of 2006 constitute a second short-term date for the Jordanian stock market (Fig. 5). The subprime crisis is revealed also in the spectral density pattern of gold (Fig. 10), affecting thereby both the short and long term. Nevertheless, the latest recession at the end of 2019 looks, for the time being, as only affect the short term. (Figs 3, 4, 5, 6, 7, 8, 9, 10)

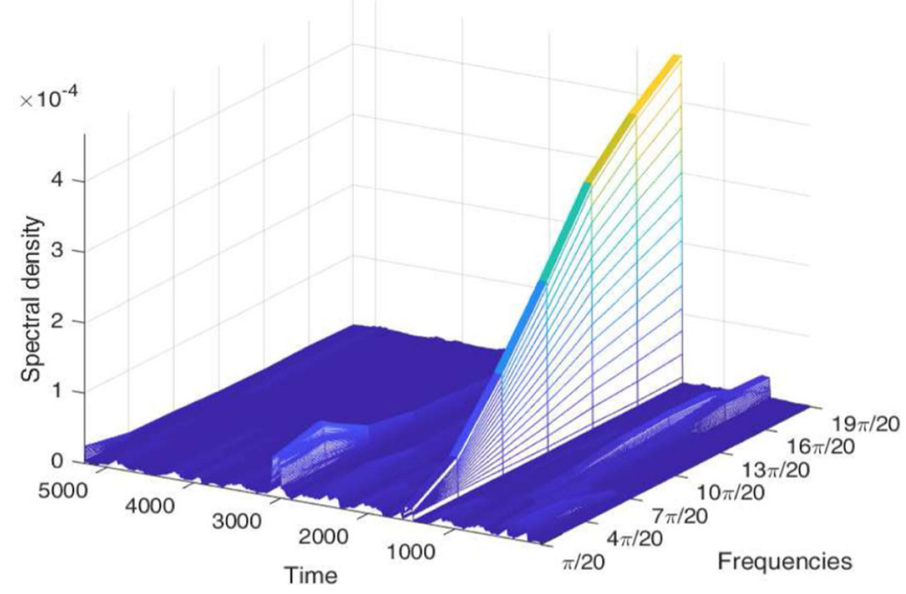

Fig. 2 Evolutionary spectral density of Tunisian Stock returns 


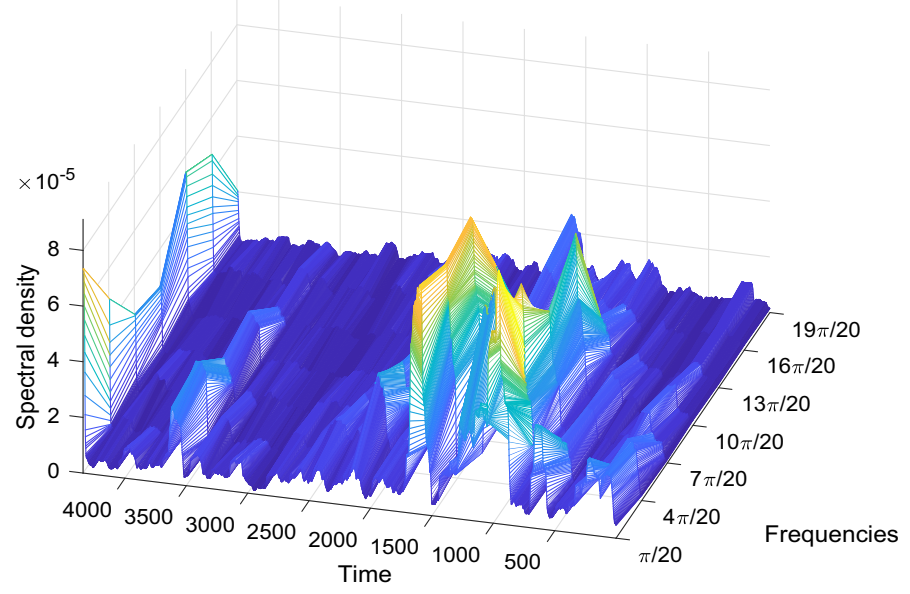

Fig. 3 Evolutionary spectral density of Morocco Stock returns

For the Moroccan stock exchange (Fig. 3) the two dates of early 2006 and mid2007, as well as the last observations date (end 2019 and beginning 2020), seem to affect the short and long-term frequencies. These dates correspond to the main events that characterized the Moroccan market. Either the increase in the market capitalization-to-GDP ratio jumped from $23.8 \%$ in 2002 to $86.1 \%$ in 2006 following multiple initial public offerings (IPOs); and the 2007 global financial crisis that damaged the prices of traded securities, in addition to the global recession and the COVID-19 effect at the end of 2019 and the beginning of 2020. These factors have an important short and long term effect on the Moroccan stock market. The three most volatile markets (Dubai, Egypt, Saudi Arabia) have undergone frequent fluctuations and share the same dates of change in their spectral density (notably 2006 and 2008). For this period, the subprime crisis was the major event that hit hard these financial markets. Moreover, for the Dubai stock market, a remarkable growth of $150 \%$ in 2004 and $190 \%$ in 2005 , followed by a correction of $24 \%$ in 2006, affected the whole gulf region. Besides, in 2014, $\mathrm{MSCI}^{8}$ included the United Arab Emirates (of which Dubai is a part) in the emerging markets category. The evolutionary spectral density shows both short- and long-term fluctuations for this date. For the Egyptian stock market, a second fluctuation appears in 2011. This period was critical for all of Egypt following the Arab Spring revolution. The

\footnotetext{
${ }_{8}$ Morgan Stanley Capital International.
} 


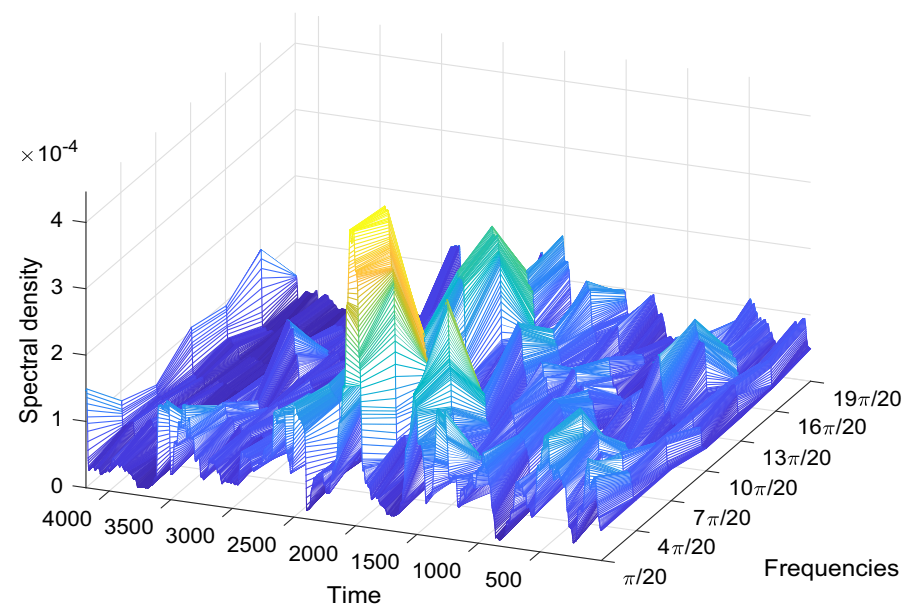

Fig. 4 Evolutionary spectral density of Egypt Stock returns

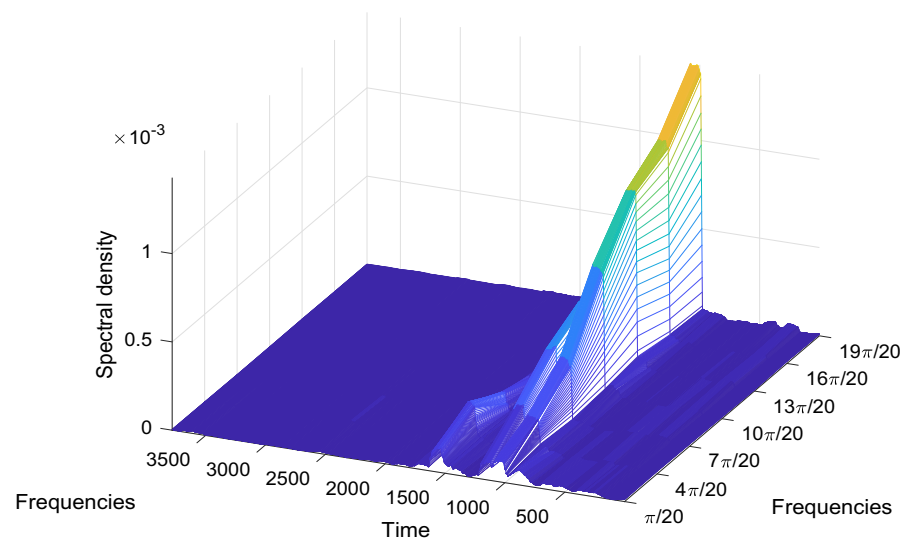

Fig. 5 Evolutionary spectral density of Jordan Stock returns 


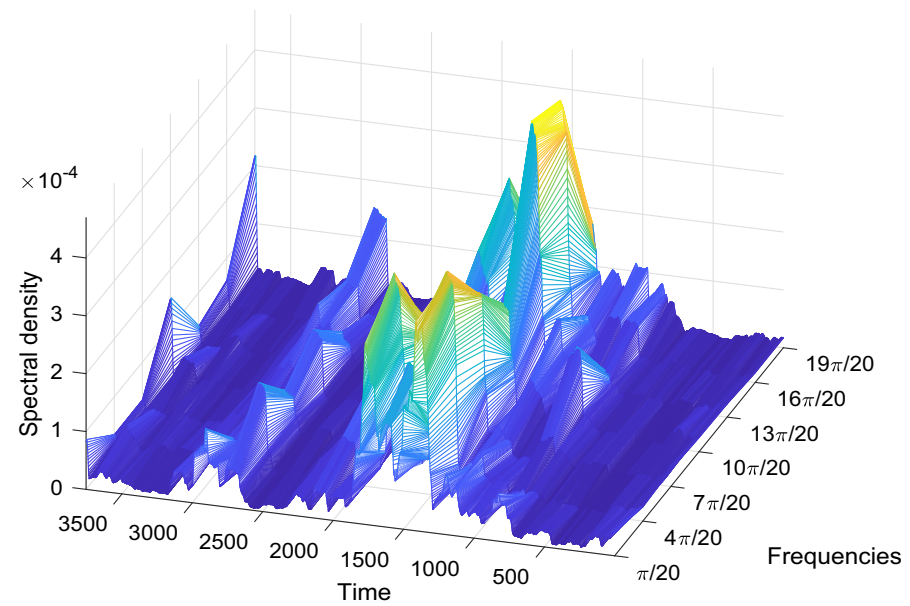

Fig. 6 Evolutionary spectral density of Saudi Arabi Stock returns

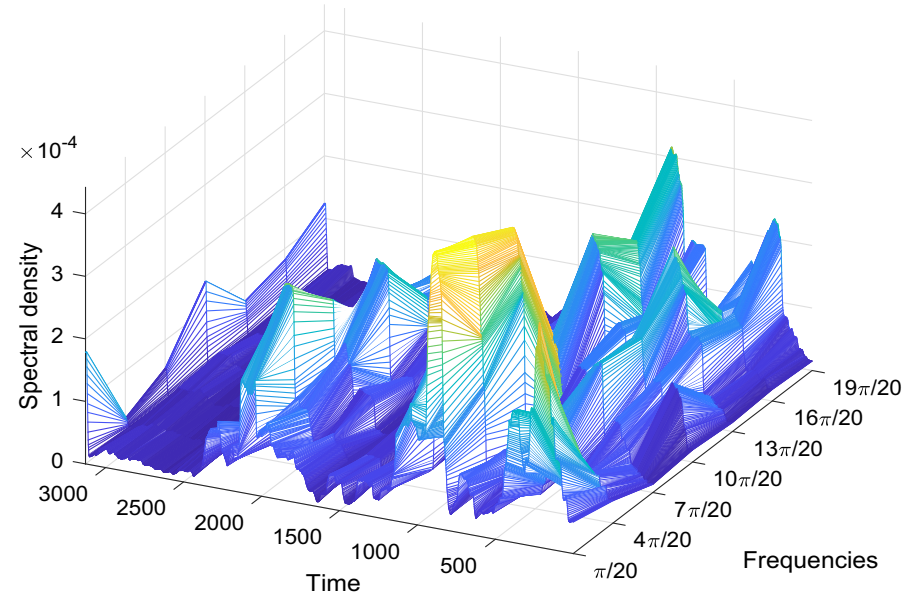

Fig. 7 Evolutionary spectral density of Dubai (UAE) Stock returns 


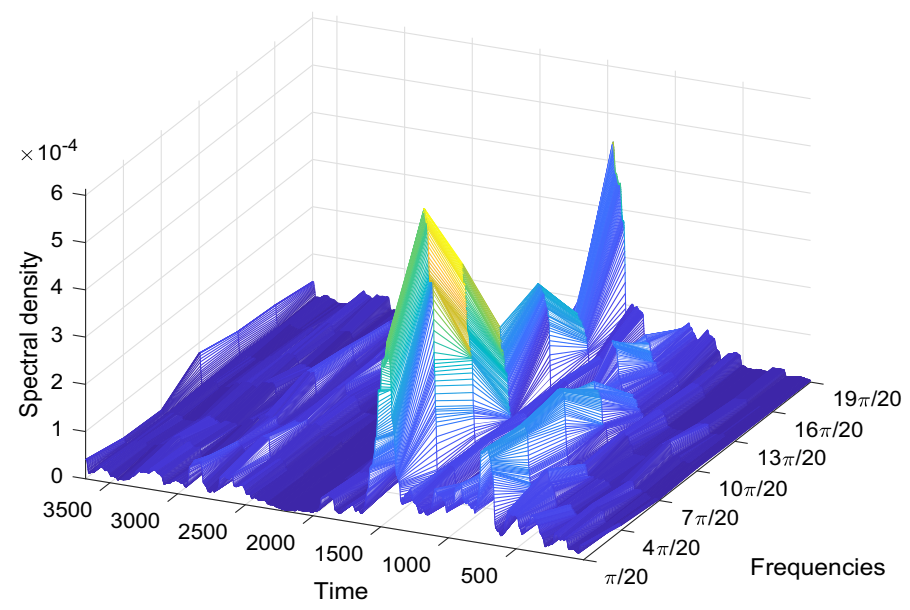

Fig. 8 Evolutionary spectral density of Qatar Stock returns

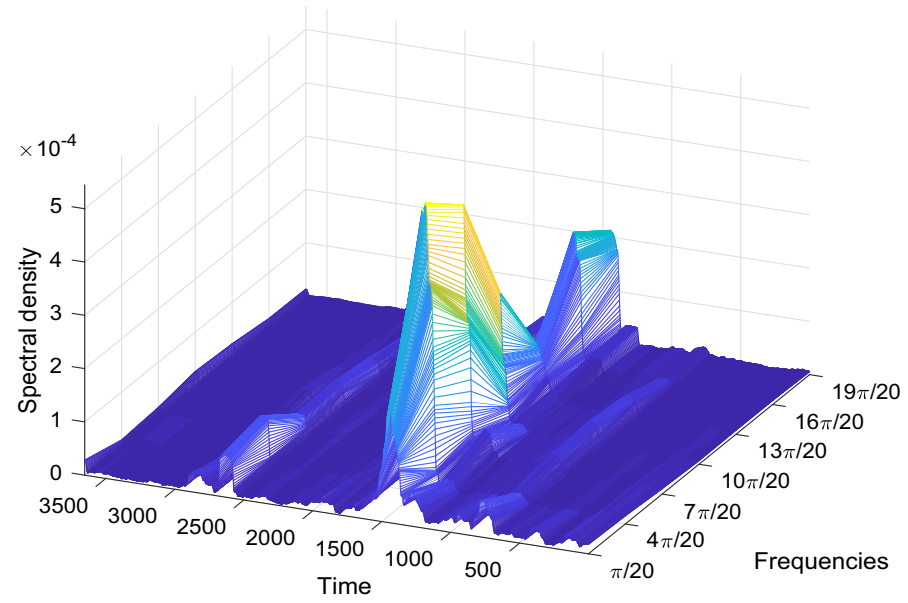

Fig. 9 Evolutionary spectral density of Oman Stock returns 


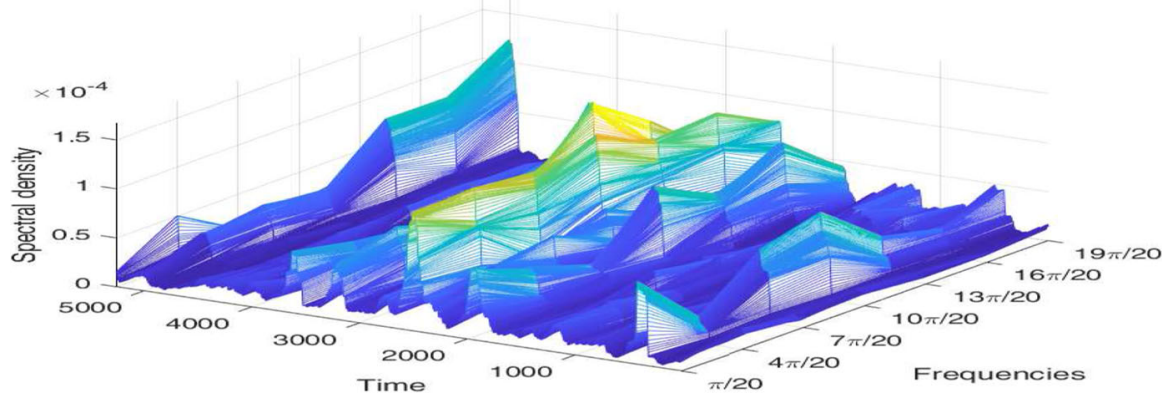

Fig. 10 Evolutionary spectral density of gold returns

\section{Tunisia-Gold coherence function}

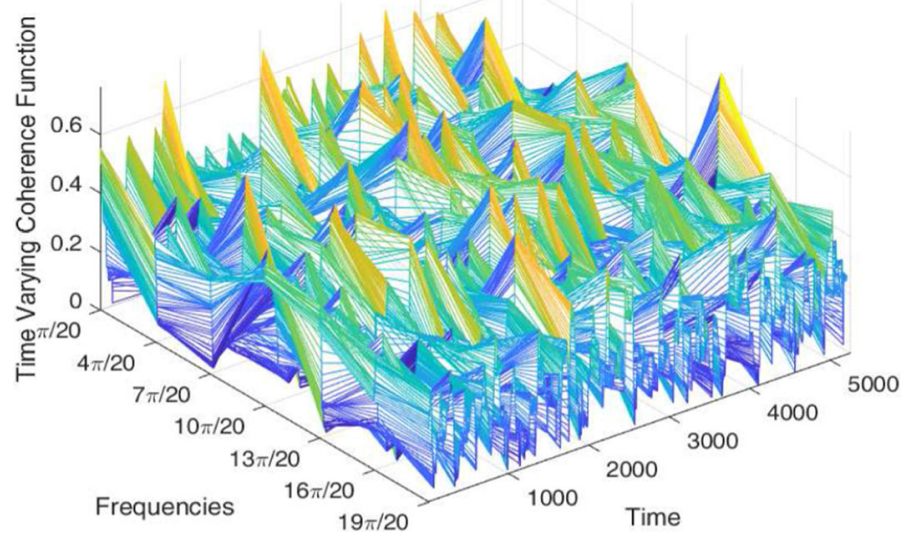

Fig. 11 Tunisian stock and gold prices coherence dynamics

market capitalization-to-GDP ratio fell from $72 \%$ in 2006 to $21 \%$ in 2011 . The effect of the end of 2019 appears also in all these markets, especially for the low frequencies (in the long term) (Figs 11, 12, 13, 14, 15, 16, 17 and 18).

Figures 19, 20, 21, 22, 23, 24, 25 and 26 plot the wavelet coherence between gold and each of the MENA stock indices, where strong (weak) co-movements are given in red (blue) color. The horizontal axis denotes the time domain while the vertical axis represents the frequency domain The latter is shown as the scale (number of days), with a higher frequency indicating a longer investment horizon up to 1,024 days. The black contours reflect regions with significance at the 5\% level, as estimated from 1,000 Monte Carlo simulations. The directional arrows show the lead-lag relationship and the sign of the relationship.

The estimated results show that the time-frequency plane is mostly dominated by blue color for each MENA stock index, reflecting the weak relationship between gold and the stock index for the entire sample period over many frequencies and thereby the possibility of diversification benefits from combining gold with the 


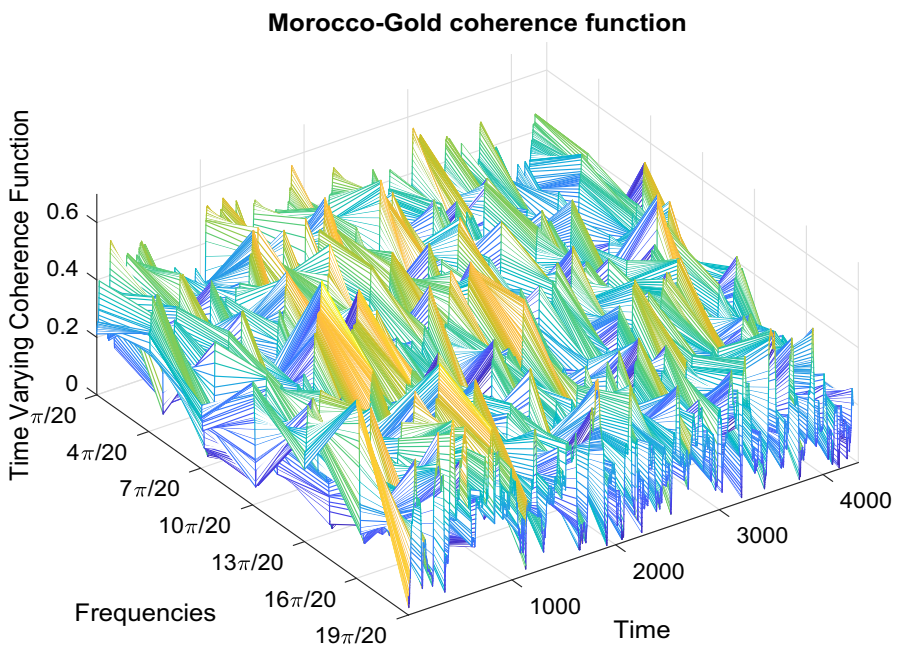

Fig. 12 Morocco stock and gold prices coherence dynamics

\section{Egypt-Gold coherence function}

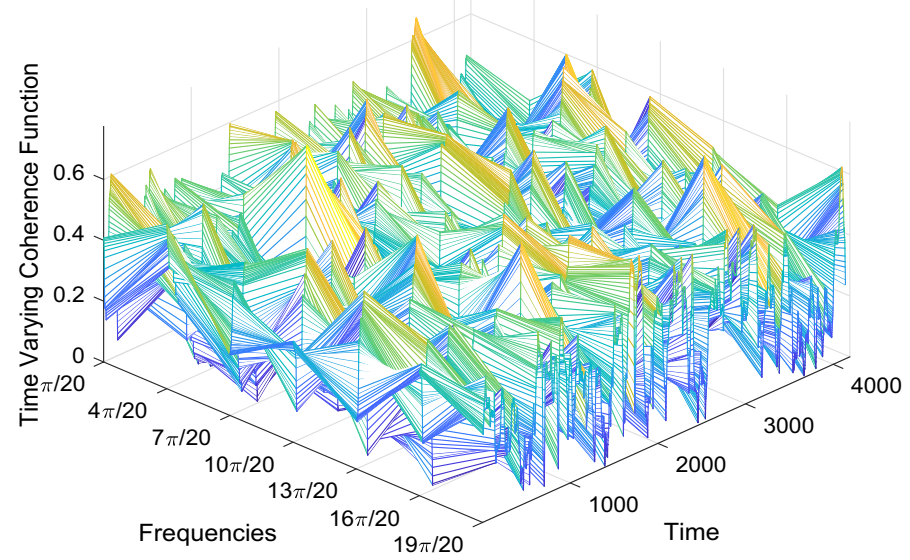

Fig. 13 Egytian stock and gold prices coherence dynamics

stock index. This outcome is in agreement with the Table 2 displaying low level of correlation. Only small areas of significant relationship are observed, especially around the end of 2006-2010.

Most of the significant degree of relationship between gold and stock index returns is for the period 2002-2014 across the 128-256 days frequency band (except for the stock index of Egypt and Saudi Arabia where a significant relationship is observed in the 512 and 1024 days frequency band, respectively). The relationship is relatively weak for the 1-32 days and frequency bands, suggesting that combining 


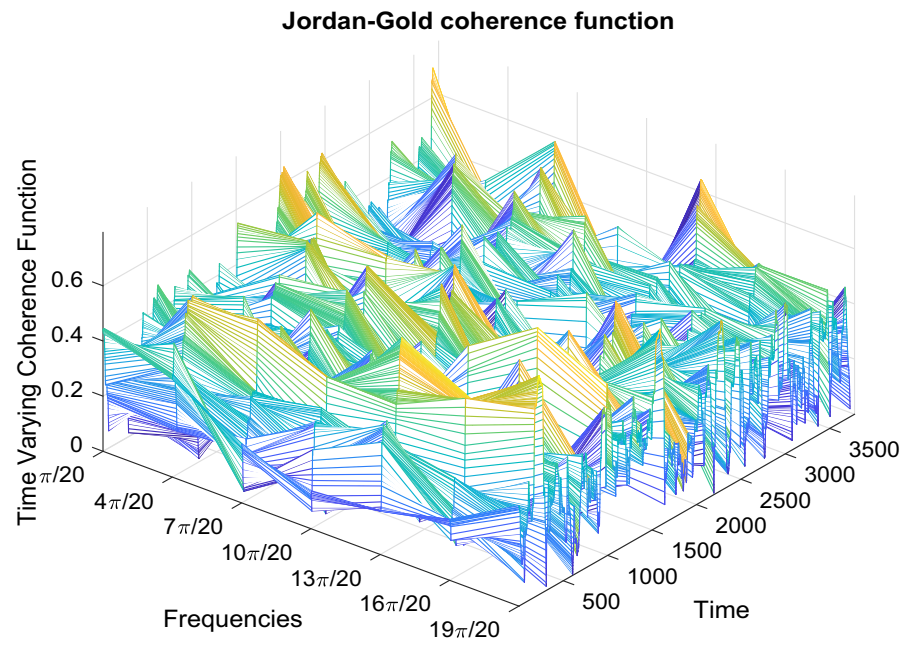

Fig. 14 Jordan stock and gold prices coherence dynamics

\section{Saudi Arabia-Gold coherence function}

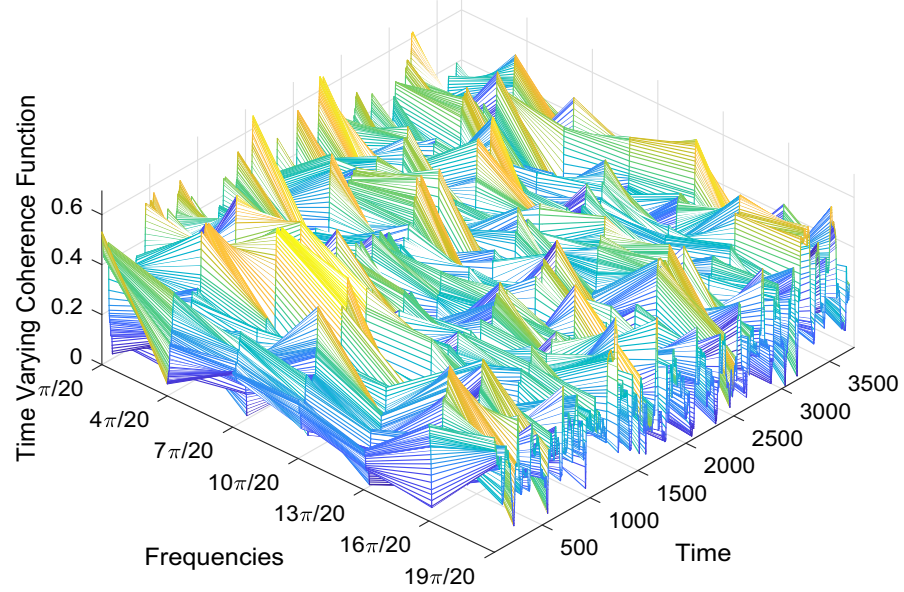

Fig. 15 Saudi Arabi stock and gold prices coherence dynamics

gold with the stock index in portfolios may generate some diversification benefits in the short-term. We notice the arrow point $\rightarrow$, which indicates an in-phase relationship across the 128-512 days band. This implies a positive relationship between gold and the stock index returns during the period 2006M10-2010M11, especially for Egypt, Saudi Arabia, Dubai, Qatar, and Oman. The arrow point $\leftarrow$, which indicates an out-of-phase relationship and thus a negative relationship, is shown for the case of Saudi Arabia during the first sample period around the 5121024 days frequency band. As for the arrow point $\nearrow$, it is apparent in Egypt around the beginning of the sample period in the 256-512 days band, reflecting the fact that 


\section{Dubai (UAE)-Gold coherence function}

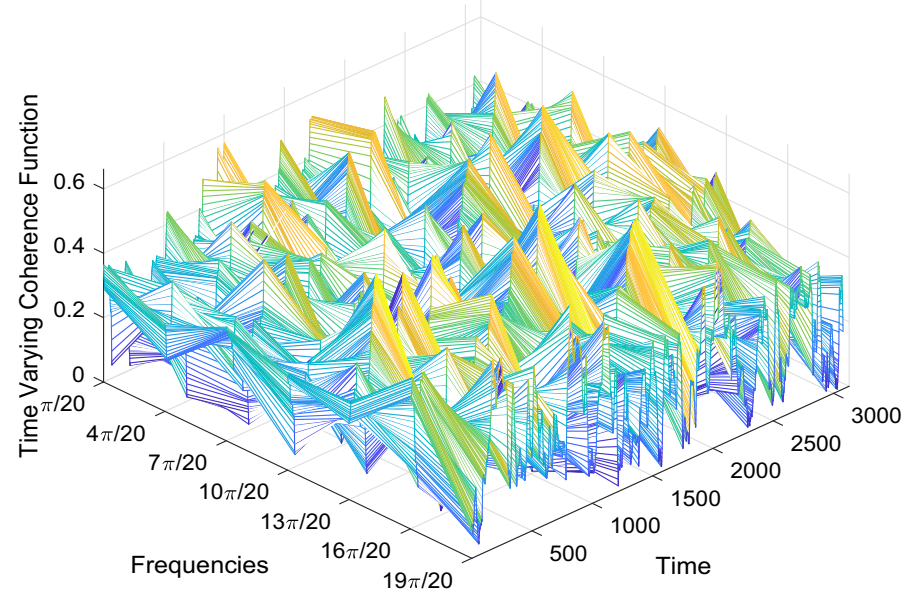

Fig. 16 Dubai (UAE) stock and gold prices coherence dynamics

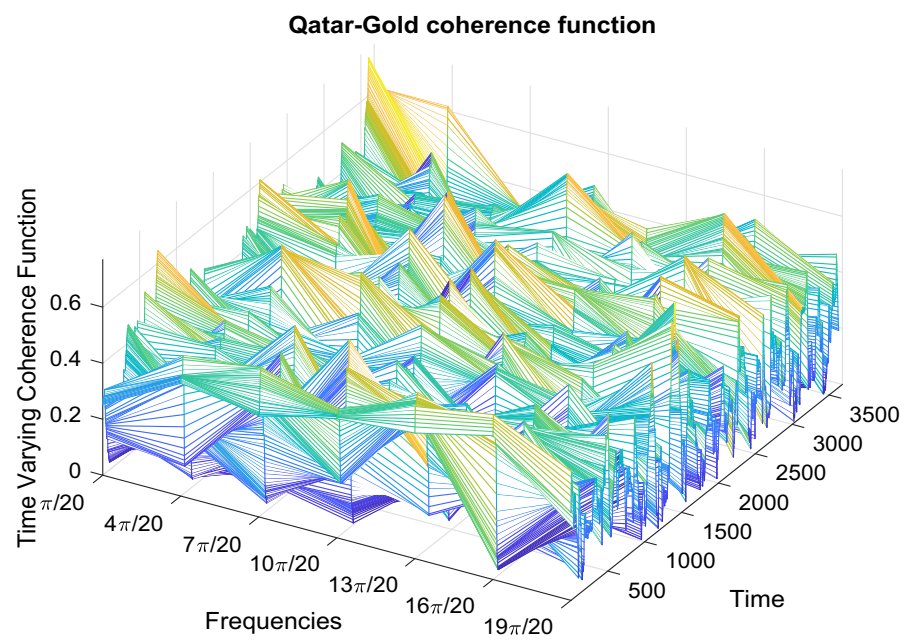

Fig. 17 Qatar stock and gold prices coherence dynamics

gold returns lead the returns of the stock index in the long-term. It is also shown in Dubai around the 512 days frequency band during the COVID-19 outbreak. However, during the middle of the sample period, the presence of the arrow point $\searrow$ in the 256-512 days band in Morocco, Egypt, Jordan, Dubai, Qatar and Oman suggests that that the stock index returns lead gold returns in the medium to long terms. Furthermore, the presence of arrow point $\nwarrow$ indicates that gold returns lag the returns of the stock index, which is especially the case for Qatar toward the end of the sample period and at the high frequency band. 


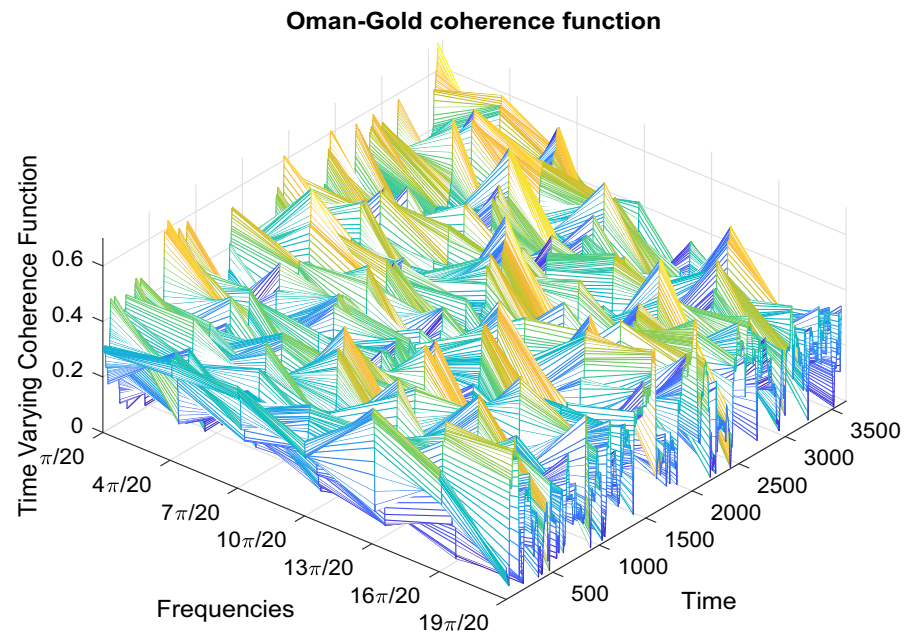

Fig. 18 Oman stock and gold prices coherence dynamics

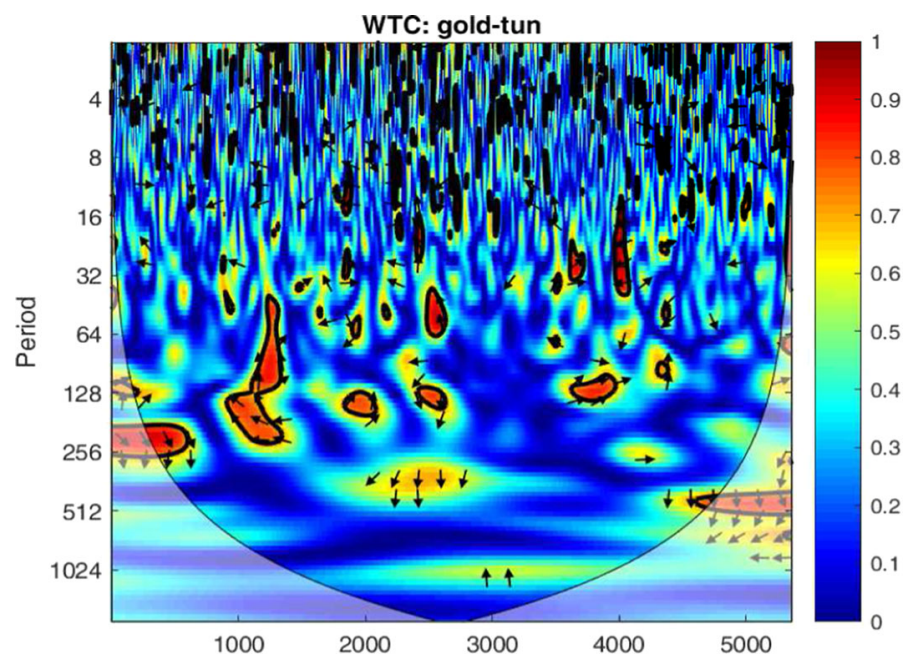

Fig. 19 Squared wavelet coherence between Tunisian stock and gold prices

The figures from 11 to 18 show a common feature in the fluctuation of the comovement between the stock market indexes and the price of gold, with an equal range between 0 and a bit more than 0.6. Notably, we notice some differences between the co-movements in the short-term, medium-term, and long-term. Specifically, the short-term co-movement shows more peaks whereas the longterm co-movement is relatively more stable. Furthermore, we provide in Table 2 the Pearson correlation between gold and stock market returns. Gold is negatively correlated with Saudi Arabia, Jordan and Qatar, and positively correlated with the 


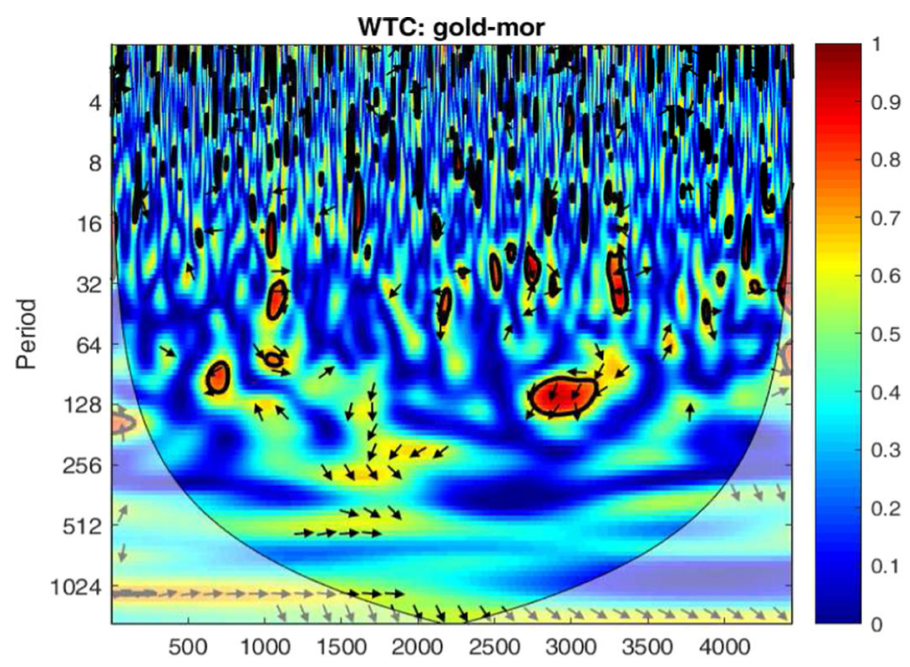

Fig. 20 Squared wavelet coherence between Morocco stock and gold prices

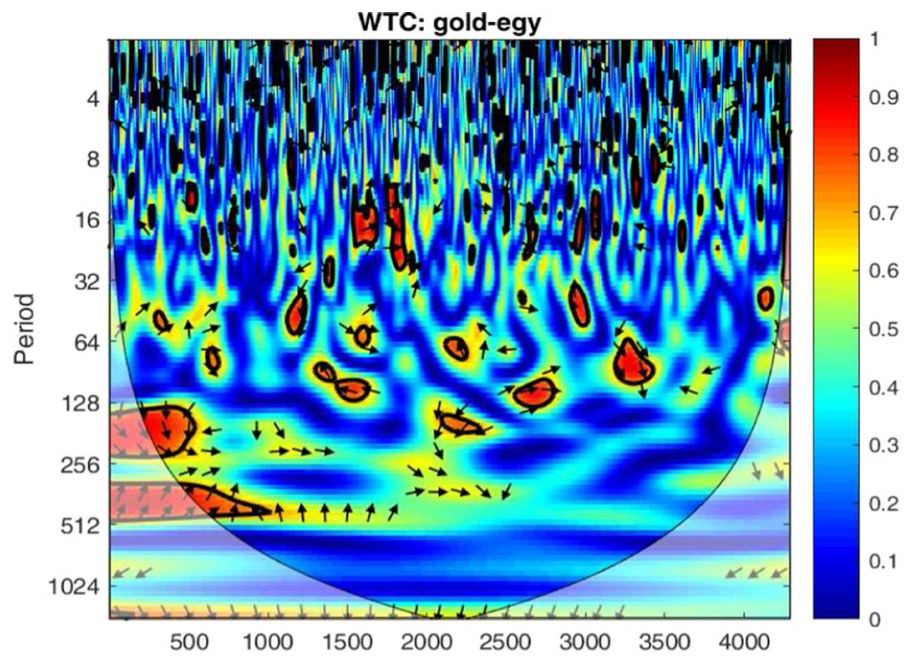

Fig. 21 Squared wavelet coherence between Egytian stock and gold prices

rest of MEN countries, although in all cases the correlation coefficients are very low and too close to zero, which suggests potential diversification benefits.

Once the dynamic variance-covariance is estimated using both the DCC-GARCH model, wavelet approach, and the spectral method, the weight for each asset is determined then optimal portfolios are constructed (Eqs. 37 and 38). As the frequency approach (wavelet and spectral) discloses various series of consistency, we will consider the best ten alternative proposals for wavelet and the seven one from the spectral method, each one corresponding to a specific frequency. Then the return of each portfolio will be computed as well as its variance (Tables 3 and 4). 


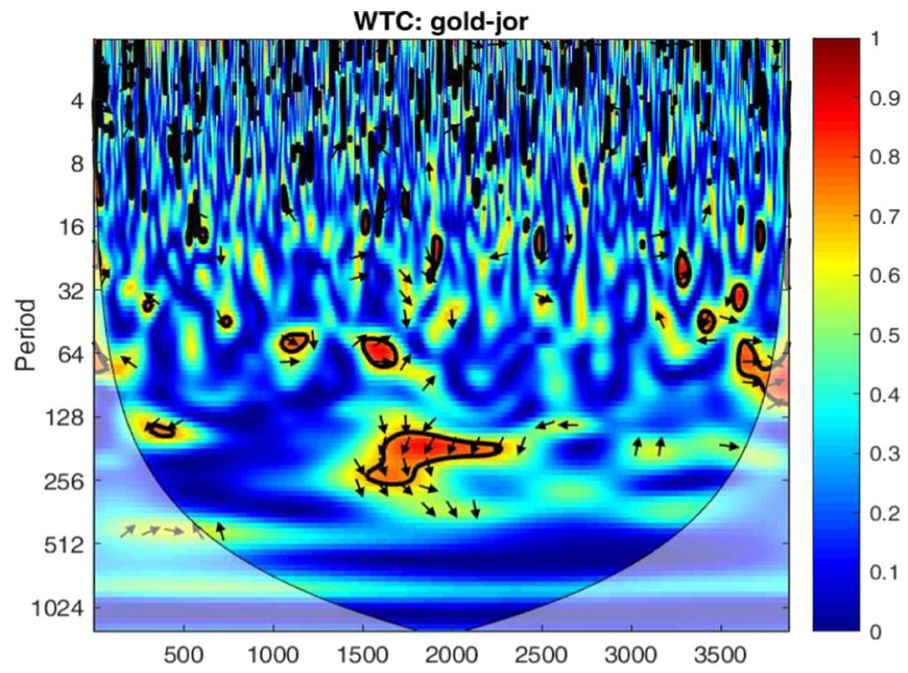

Fig. 22 Squared wavelet coherence between Jordan stock and gold prices

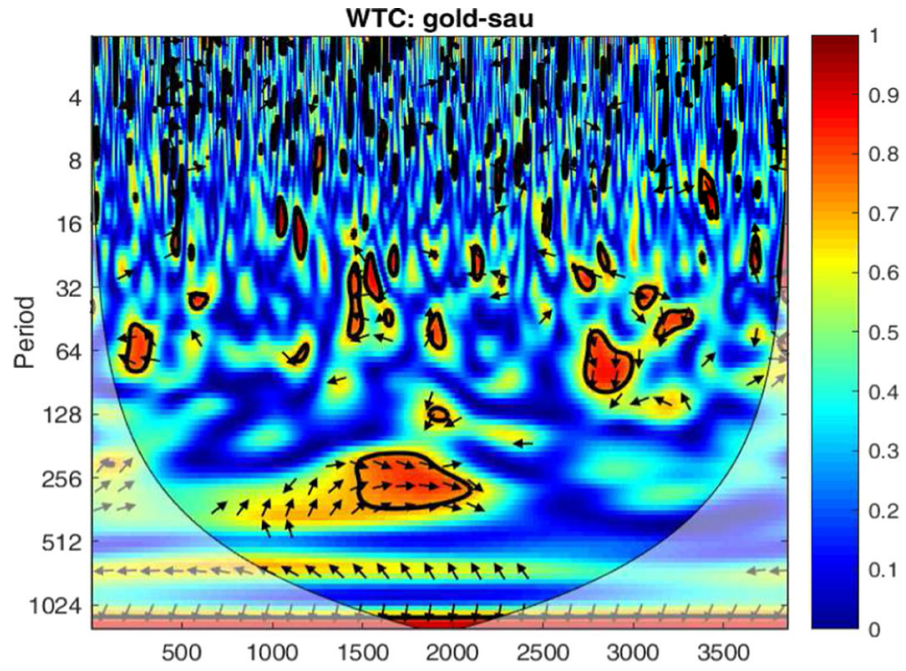

Fig. 23 Squared wavelet coherence between Saudi Arabi stock and gold prices

For each stock market, the variances relating to portfolios composed in the presence of gold are lower than those relating to their stock market indices. Our conclusion indicates that a portfolio with gold can help to reduce investors' risk. The analysis of Table 3 is based on a comparison of the (return, variance) couple between our seven portfolios estimated by the spectral analysis, ten portfolios estimated by the wavelet approach, and the famous DCC-GARCH model. The model providing the largest stock return and the smallest standard deviation is considered to be the most effective in measuring gold coverage. The results are mixed. The main results prove 


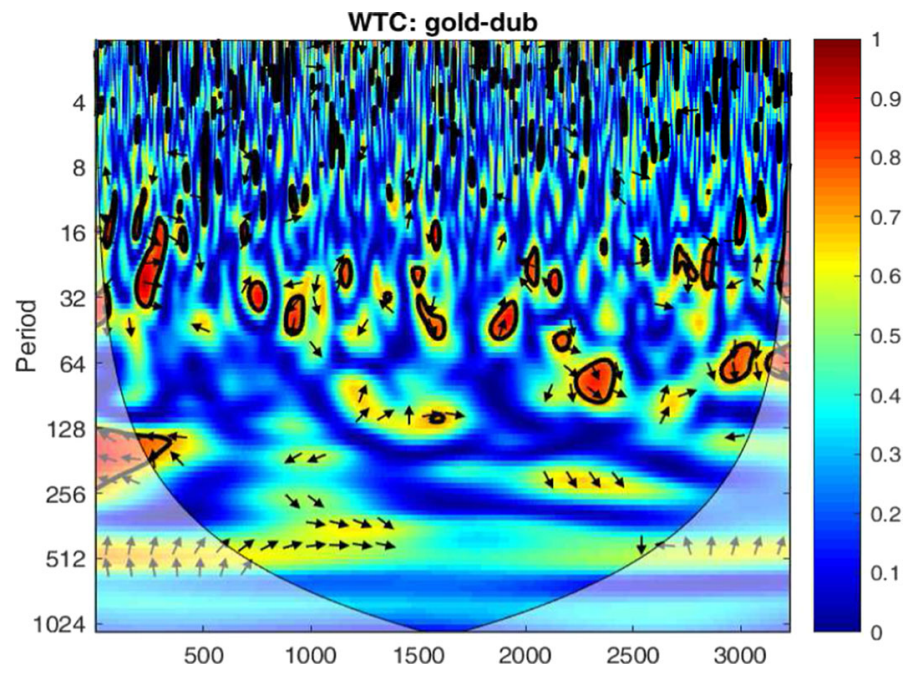

Fig. 24 Squared wavelet coherence between Dubai (UAE) stock and gold prices

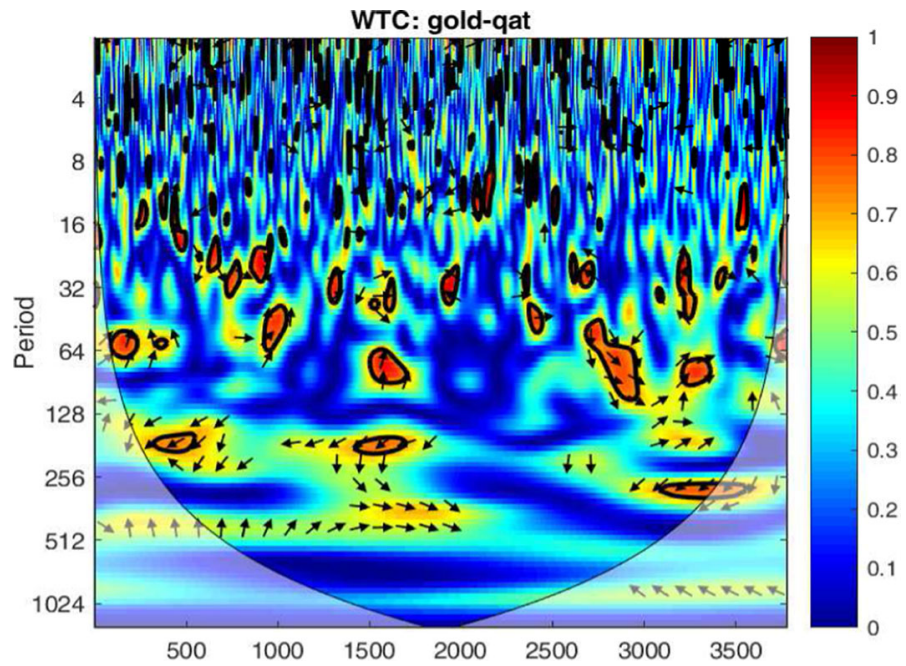

Fig. 25 Squared wavelet coherence between Qatar stock and gold prices

that our approach announces lower variances, for all countries than that proposed by the famous DCC-GARCH model and wavelet method (at least for one portfolio among the seven). Wavelet method presents portfolio with a high variance but in five cases also a higher return (P1 for Morocco and UAE, P6 for Jordan and Egypt, P7 for Tunisia and Egypt in table 4). The wavelet approach fails in variance reduction compared to the other two approaches but performs well in terms of returns that may attract risk-averse investors. However, by referring to the table 3 , the taken countries sample can be split into two subgroups. The first includes 


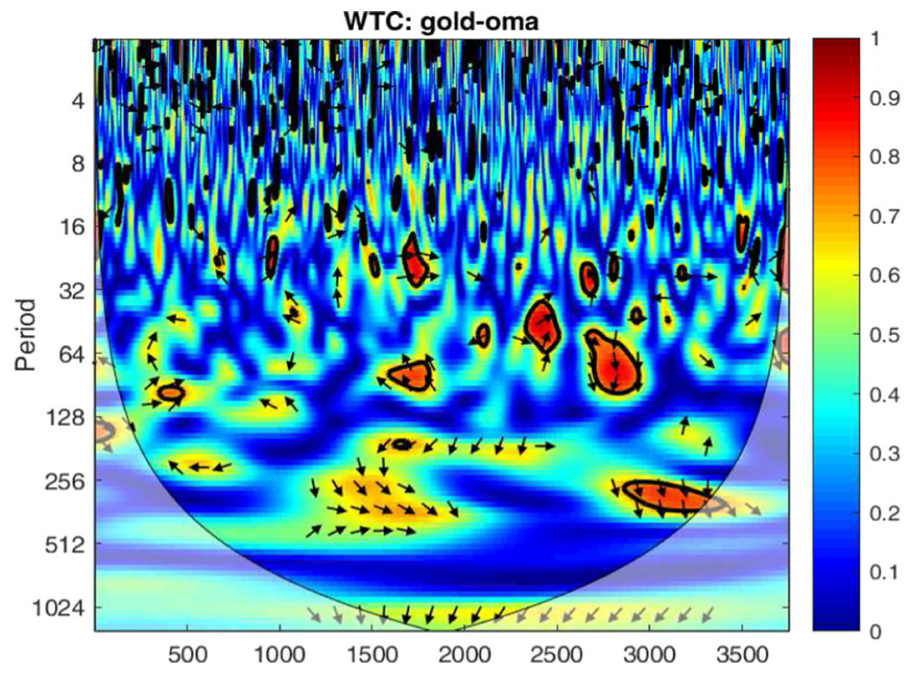

Fig. 26 Squared wavelet coherence between Oman stock and gold prices

Table 2 Correlation between gold and stock market returns

\begin{tabular}{ll}
\hline & Pearson correlation with Gold \\
\hline Tunisia & 0.0041 \\
Morocco & 0.0088 \\
Egypt & 0.0180 \\
Qatar & -0.0014 \\
Saudi Arabia & -0.0500 \\
Dubai(UAE) & 0.0049 \\
Jordan & -0.0344 \\
Oman & 0.0241 \\
\hline
\end{tabular}

Tunisia, Oman, Qatar, Dubai, and Saudi Arabia. The results prove a total superiority of the spectral analysis in the construction of hedging portfolios compared to the DCC-GARCH model. With a higher return and lower volatility, choosing an optimal portfolio is obvious. The second includes Morocco, Egypt, and Jordan. For these three stock markets, the statistical results of the spectral analysis are inconclusive. Despite its superiority through the variance measure (lower variance), but the return of constructed portfolios is also lower than that of the DCC-GARCH. 
Table 3 Mean and Variance of portfolio (Spectral and DCC-GARCH approach) $\left(\times 10^{-4}\right)$

\begin{tabular}{llllllllll}
\hline & & $P_{\pi / 20}$ & $P_{4 \pi / 20}$ & $P_{7 \pi / 20}$ & $P_{10 \pi / 20}$ & $P_{13 \pi / 20}$ & $P_{16 \pi / 20}$ & $P_{19 \pi / 20}$ & $P_{D C C-G A R C H}$ \\
\hline Tunisia & $r_{t}$ & 3,2886 & 3,6565 & 3,5256 & 3,0960 & 3,2555 & 3,1212 & 3,2523 & 3,3787 \\
& var & 0,3459 & 0,2804 & 0,2595 & 0,2605 & 0,2635 & 0,2622 & 0,2677 & 0,3814 \\
\multirow{2}{*}{ Morocco } & $r_{t}$ & 2,5633 & 2,3316 & 2,4556 & 2,2452 & 2,3589 & 2,5463 & 2,5493 & 2,6252 \\
& var & 0,3920 & 0,3710 & 0,3689 & 0,3728 & 0,3723 & 0,3869 & 0,3888 & 0,3697 \\
Egypt & $r_{t}$ & 3,7390 & 3,8878 & 3,1733 & 3,5157 & 3,6479 & 3,6194 & 3,4291 & 4,0537 \\
& var & 1,0579 & 1,0577 & 1,0043 & 0,9820 & 0,9911 & 0,9912 & 1,1034 & 0,9881 \\
Oman & $r_{t}$ & 2,5689 & 3,0277 & 2,8086 & 2,5772 & 1,7490 & 2,0709 & 1,9528 & 2,4883 \\
& var & 0,5655 & 0,5861 & 0,5793 & 0,5371 & 0,6015 & 0,5708 & 0,5949 & 0,5827 \\
\multirow{2}{*}{ Jordan } & $r_{t}$ & 1,6525 & 1,9818 & 2,1761 & 1,7012 & 1,9711 & 1,9367 & 1,7578 & 2,1962 \\
& var & 0,6774 & 0,5853 & 0,5394 & 0,5636 & 0,5530 & 0,5712 & 0,5950 & 0,6799 \\
\multirow{2}{*}{ Qatar } & $r_{t}$ & 4,2819 & 4,3268 & 4,4206 & 5,0541 & 4,3285 & 5,0821 & 4,6451 & 4,7944 \\
& var & 0,8117 & 0,7798 & 0,7910 & 0,7146 & 0,7696 & 0,7424 & 0,8291 & 0,8128 \\
Dubai & $r_{t}$ & 2,7628 & 2,6558 & 2,4535 & 2,0254 & 2,1013 & 2,4964 & 1,6440 & 2,5359 \\
& var & 0,9089 & 0,8482 & 0,8835 & 0,8607 & 0,8498 & 0,8267 & 0,8860 & 0,9249 \\
\multirow{2}{*}{ Saudi } & $r_{t}$ & 4,8288 & 4,5892 & 4,4861 & 3,9741 & 4,5431 & 4,1550 & 3,1018 & 4,4503 \\
Arabia & var & 0,9065 & 0,8430 & 0,8236 & 0,8527 & 0,8006 & 0,8685 & 0,9117 & 0,8836 \\
\hline
\end{tabular}

We cannot, therefore, decide about the superiority of our approach. To do this, we used the hedging performance ratio through variance reduction, widely adopted in the literature by (Hammoudeh et al. 2010; Chkili 2016) among others (Eq. 39, array (Table 5). The mean value of $w_{s g}$ of the seven portfolios built according to spectral analysis and the DCC-GARCH model for each country is reported in the Table 6. The table clearly shows the out-performance of our approach over the second. A total superiority of this ratio (for all portfolios) is marked for Tunisia, Dubai, and Jordan stock markets. For the rest, the hedging performance ratio of the built portfolios exceeds that of the DCC-GARCH model for at least one case. We could then decide about the superiority of the spectral analysis on the Morocco, Egypt, and Jordan stock markets. Therefore, our new approach outperforms the old measure for all countries of the MENA zone. We will focus, thereafter, on the $w_{s g}$ optimal portfolio values for each country corresponding to the largest Hedge ratio (Table 6) and the hedging performance (Table 5). The optimal gold weighting varies from $28.81 \%$ for Egypt (corresponding to the best hedging performance ratio of around 73.91 ) to $82.74 \%$ for Tunisia (corresponding to the best ratio hedging performance of around 56.09). These results coincide with the spectral density properties of each market. Countries with the most stable density (Tunisia, Oman, Morocco, and 


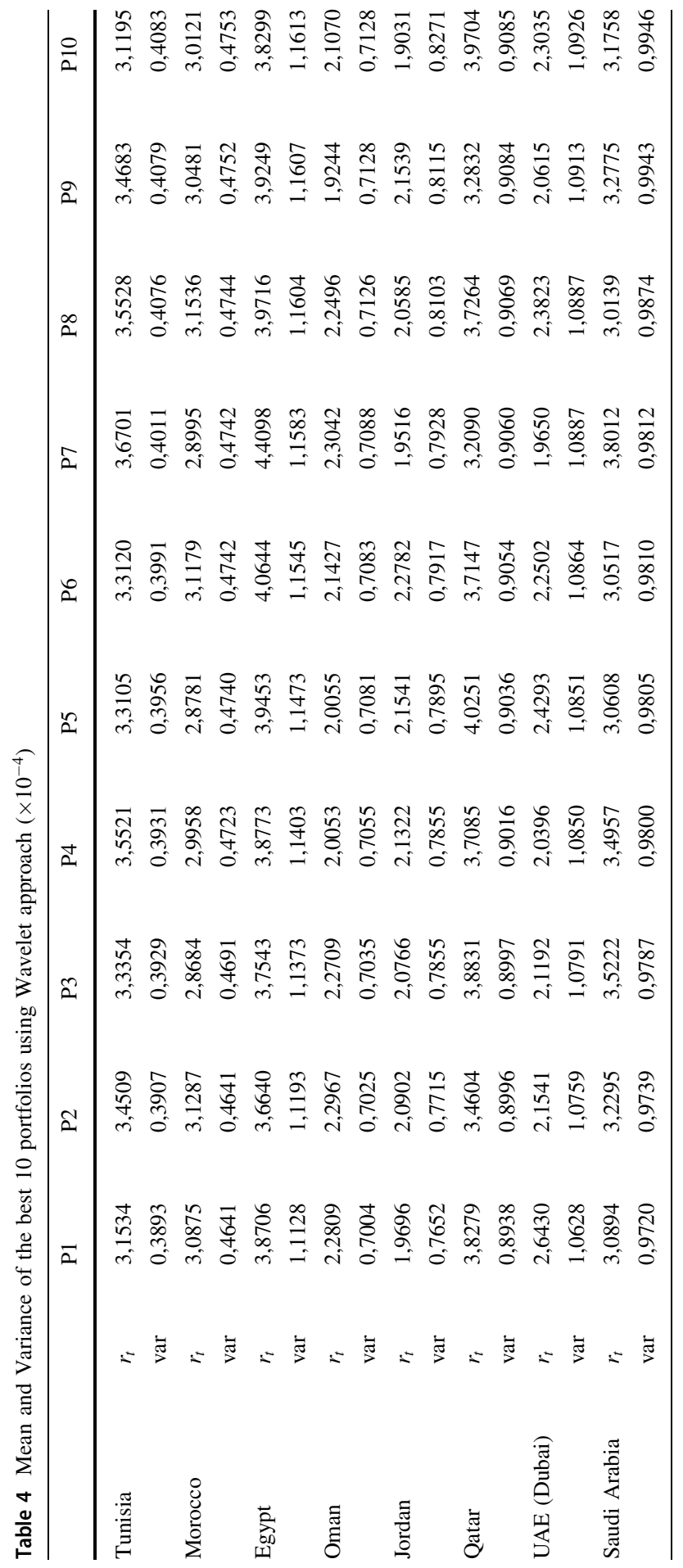


Table 5 Hedging performance in terms of variance reduction

\begin{tabular}{lllllllll}
\hline & Tunisia & Morocco & Egypt & Oman & Qatar & Dubai & Saudi Arabia & Jordan \\
\hline$P_{\pi / 20}$ & 41,46 & 36,71 & 71,89 & 50,75 & 66,09 & 75,72 & 69,23 & 71,51 \\
$P_{4 \pi / 20}$ & 52,56 & 40,10 & 71,89 & 48,96 & 67,42 & 77,34 & 71,39 & 75,38 \\
$P_{7 \pi / 20}$ & 56,09 & 40,43 & 73,31 & 49,55 & 66,95 & 76,40 & 72,05 & 77,31 \\
$P_{10 \pi / 20}$ & 55,92 & 39,81 & 73,91 & 53,22 & 70,14 & 77,00 & 71,06 & 76,29 \\
$P_{13 \pi / 20}$ & 55,42 & 39,89 & 73,66 & 47,61 & 67,84 & 77,29 & 72,83 & 76,74 \\
$P_{16 \pi / 20}$ & 55,63 & 37,53 & 73,66 & 50,29 & 68,98 & 77,91 & 70,52 & 75,97 \\
$P_{19 \pi / 20}$ & 54,70 & 37,23 & 70,68 & 48,19 & 65,36 & 76,33 & 69,06 & 74,97 \\
$P_{D C C-G A R C H}$ & 35,45 & 40,31 & 73,74 & 49,25 & 66,04 & 75,29 & 70,01 & 71,40 \\
\hline & & & & & & & &
\end{tabular}

Table 6 Mean weight level in percentage

\begin{tabular}{lllllllll}
\hline & Tunisia & Morocco & Egypt & Oman & Qatar & Dubai & Saudi Arabia & Jordan \\
\hline$P_{\pi / 20}$ & 25,53 & 36,08 & 82,03 & 42,36 & 64,56 & 74,19 & 66,00 & 35,71 \\
$P_{4 \pi / 20}$ & 22,77 & 32,23 & 83,77 & 34,04 & 60,17 & 67,73 & 60,68 & 36,34 \\
$P_{7 \pi / 20}$ & 17,26 & 30,86 & 75,04 & 28,61 & 55,05 & 62,60 & 54,28 & 29,91 \\
$P_{10 \pi / 20}$ & 15,30 & 21,91 & 71,19 & 25,05 & 53,77 & 63,74 & 55,82 & 29,58 \\
$P_{13 \pi / 20}$ & 13,79 & 16,62 & 71,72 & 22,72 & 46,50 & 63,88 & 54,27 & 27,98 \\
$P_{16 \pi / 20}$ & 13,05 & 16,64 & 64,71 & 21,05 & 45,29 & 60,68 & 48,34 & 24,90 \\
$P_{19 \pi / 20}$ & 11,83 & 15,23 & 62,63 & 19,63 & 45,09 & 57,62 & 50,28 & 25,67 \\
$P_{D C C-G A R C H}$ & 27,33 & 28,77 & 67,49 & 30,01 & 50,39 & 61,08 & 52,26 & 33,34 \\
\hline
\end{tabular}

Jordan) have the highest gold share $(82.74 \%, 74.95 \%, 69.14 \%$, and $70.09 \%$ respectively) in the portfolios, minimizing thus the total variance. In the countries whose spectral density fluctuates widely (Egypt and Dubai), the use of gold in their investment portfolio is the lowest (28.81\% and $39.32 \%$ respectively). Qatar and Saudi Arabia constitute their optimal portfolios with a relatively balanced composition between stocks and gold with a gold average percentage in the order of $46.23 \%$ and $45.73 \%$ respectively.

However, gold continues to be a reliable hedge, especially during the covid-19 crisis. The optimal allocation between gold and stocks depends primarily on the stock market and its ability to absorb shocks. The results revealed that the more the market is volatile and adverse circumstances occur, the more investors switch to gold. Therefore, gold is a good tool to hedge against the risk of a crash in stock prices for stable markets with low spectral density. 


\section{Conclusion}

In this paper, we introduce a new method of estimating the hedge ratio. We propose seven portfolio structures based on spectral analysis and then evaluate them by comparison with the classical DCC-GARCH method and best ten portfolios constructed by wavelet method. As such, we distinguish the properties of hedging cycles for high and low frequency. By applying the frequency method to some countries of the MENA region, we demonstrate its ability to reduce the estimated risk by the coverage efficiency ratio.

This work led to several empirical results:

- By using the DCC-GARCH model, wavelet method and the spectral analysis, all methods reduce variance compared to the unhedged portfolio. Gold keeps always its hedging character.

- By using the hedge effectiveness ratio based on variance reduction, spectral analysis outperforms both the DCC-GARCH model and wavelet method in the construction of hedge portfolios.

- The wavelet approach fails in variance reduction compared to the other two approaches but performs well in terms of returns that may attract risk-averse investors.

- The use of gold in investment portfolios can reduce the variance by more than $70 \%$ for the stock market index of Egypt, Dubai, Jordan and Saudi Arabia and by at least $35 \%$ of the rest of the countries studied, especially for the new suggested methodology.

- The optimal composition between gold and stocks depends essentially on the spectral density of each market. A stock market index with a stable spectral density requires more investments in gold than a stock market index with an unstable spectral density.

Future research can consider a more detailed comparison with recent frequencybased techniques, including wavelets, to refine the portfolio implications. Another extension can cover emerging countries from other regions such as South America, Europe and Asia-Pacific.

Acknowledgements The authors thank Pr. Hans Amman and the anonymous referees for useful comments. The paper also benefited from comments by Pr. Raimundo Soto at the 27th ERF conferences. This work was sponsored by the Economic Research Forum (ERF) and has benefited from both financial and intellectual support. The contents and recommendations do not necessarily reflect ERF's views.

\section{References}

Addison, P. S. (2017). The illustrated wavelet transform handbook: introductory theory and applications in science, engineering, medicine and finance. CRC Press.

Aguiar-Conraria, L., \& Soares, M. J. (2011). Oil and the macroeconomy: using wavelets to analyze old issues. Empirical Economics, 40(3), 645-655.

Baruník, J., Kočenda, E., \& Vácha, L. (2016). Gold, oil, and stocks: Dynamic correlations. International Review of Economics \& Finance, 42, 186-201. 
Basher, S. A., \& Sadorsky, P. (2016). Hedging emerging market stock prices with oil, gold, vix, and bonds: A comparison between dcc, adcc and go-garch. Energy Economics, 54, 235-247.

Baumöhl, E., \& Lyócsa, ک̌ . (2017). Directional predictability from stock market sector indices to gold: A cross-quantilogram analysis. Finance Research Letters, 23, 152-164.

Baur, D. G., \& McDermott, T. K. (2010). Is gold a safe haven? international evidence. Journal of Banking \& Finance, 34(8), 1886-1898.

Bhatia, V., Das, D., \& Kumar, S. B. (2020). Hedging effectiveness of precious metals across frequencies: Evidence from wavelet based dynamic conditional correlation analysis. Physica A: Statistical Mechanics and its Applications, 541, 123631.

Bouri, E., Jain, A., Biswal, P., \& Roubaud, D. (2017). Cointegration and nonlinear causality amongst gold, oil, and the indian stock market: Evidence from implied volatility indices. Resources Policy, 52, 201-206.

Bouri, E., Roubaud, D., Jammazi, R., \& Assaf, A. (2017). Uncovering frequency domain causality between gold and the stock markets of china and india: Evidence from implied volatility indices. Finance Research Letters, 23, 23-30.

Bulut, L., \& Rizvanoghlu, I. (2020). Is gold a safe haven? the international evidence revisited. Acta Oeconomica, 70(4), 531-549.

Chkili, W. (2016). Dynamic correlations and hedging effectiveness between gold and stock markets: Evidence for brics countries. Research in International Business and Finance, 38, 22-34.

Ciner, C., Gurdgiev, C., \& Lucey, B. M. (2013). Hedges and safe havens: An examination of stocks, bonds, gold, oil and exchange rates. International Review of Financial Analysis, 29, 202-211.

Creti, A., Joëts, M., \& Mignon, V. (2013). On the links between stock and commodity markets volatility. Energy Economics, 37, 16-28.

Dong, M. C., Chen, C. W., Lee, S., \& Sriboonchitta, S. (2019). How strong is the relationship among gold and usd exchange rates? analytics based on structural change models. Computational Economics, 53(1), 343-366.

Dong, X., \& Yoon, S.-M. (2018). Structural breaks, dynamic correlations, and hedge and safe havens for stock and foreign exchange markets in greater china. The World Economy, 41(10), 2783-2803.

Engel, R. (2002). Dynamic conditional correlation-a simple class of multivariate garch models. Journal of Business and Economic Statistics, 20(3), 339-350.

Essaadi, E., \& Boutahar, M. (2010). A measure of variability in comovement for economic variables: a time-varying coherence function approach. Economics Bulletin, 30(2), 1054-1070.

Essaadi, E., Jouini, J., \& Khallouli, W. (2009). The asian crisis contagion: A dynamic correlation approach analysis. Panoeconomicus, 56(2), 241-260.

Ftiti, Z., Tiwari, A., Belanès, A., \& Guesmi, K. (2015). Tests of financial market contagion: Evolutionary cospectral analysis versus wavelet analysis. Computational Economics, 46(4), 575-611.

Ghosh, I., Sanyal, M. K., \& Jana, R. (2021). Co-movement and dynamic correlation of financial and energy markets: An integrated framework of nonlinear dynamics, wavelet analysis and dcc-garch. Computational Economics, 57(2), 503-527.

Gokmenoglu, K. K. and N. Fazlollahi (2015). The interactions among gold, oil, and stock market: evidence from s\&p500. Procedia Economics and Finance 25(Supp. C), 478-488.

Grinsted, A., Moore, J. C., \& Jevrejeva, S. (2004). Application of the cross wavelet transform and wavelet coherence to geophysical time series. Nonlinear processes in geophysics, 11(5/6), 561-566.

Hammoudeh, S. M., Yuan, Y., McAleer, M., \& Thompson, M. A. (2010). Precious metals-exchange rate volatility transmissions and hedging strategies. International Review of Economics \& Finance, 19(4), 633-647.

Iqbal, J. (2017). Does gold hedge stock market, inflation and exchange rate risks? an econometric investigation. International Review of Economics \& Finance, 48, 1-17.

Khalfaoui, R., Boutahar, M., \& Boubaker, H. (2015). Analyzing volatility spillovers and hedging between oil and stock markets: Evidence from wavelet analysis. Energy Economics, 49, 540-549.

$\mathrm{Ku}$, Y.-H.H., Chen, H.-C., \& Chen, K.-H. (2007). On the application of the dynamic conditional correlation model in estimating optimal time-varying hedge ratios. Applied Economics Letters, 14(7), 503-509.

Kumar, D. (2014). Return and volatility transmission between gold and stock sectors: Application of portfolio management and hedging effectiveness. IIMB Management Review, 26(1), 5-16.

Loynes, R. M. (1968). On the concept of the spectrum for non-stationary processes. Journal of the Royal Statistical Society: Series B (Methodological), 30(1), 1-20. 
Priestley, M. (1965). Evolutionary spectra and non-stationary processes. Journal of the Royal Statistical Society. Series B (Methodological) 27(2), 204-237.

Priestley, M. (1996). Wavelets and time-dependent spectral analysis. Journal of Time Series Analysis, 17(1), 85-103.

Priestley, M. B. (1988). Non-linear and non-stationary time series analysis, Volume 223. Academic Press London.

Raza, N., Shahzad, S. J. H., Tiwari, A. K., \& Shahbaz, M. (2016). Asymmetric impact of gold, oil prices and their volatilities on stock prices of emerging markets. Resources Policy, 49, 290-301.

Tiwari, A. K., Adewuyi, A. O., \& Roubaud, D. (2019). Dependence between the global gold market and emerging stock markets $(\mathrm{e} 7+1)$ : Evidence from granger causality using quantile and quantile-onquantile regression methods. The World Economy, 42(7), 2172-2214.

Torrence, C. and G. Compo (1998). A practical guide to wavelet analysis. bulletin of the american meteorological society 79: 61-78. https://doi.org/10.1175/1520-0477 (1998) 079/0061: Apgtwa [2.0.

Zhou, W. (2017). Dynamic and asymmetric contagion reactions of financial markets during the last subprime crisis. Computational Economics, 50(2), 207-230.

Ziaei, S. M. (2012). Effects of gold price on equity, bond and domestic credit: Evidence from asean +3. Procedia-Social and Behavioral Sciences, 40, 341-346.

Publisher's Note Springer Nature remains neutral with regard to jurisdictional claims in published maps and institutional affiliations. 